Animação de jatos oscilantes em fluidos viscosos usando SPH em GPU

Luiz Fernando de Souza Andrade 

SERVIÇO DE PÓS-GRADUAÇÃO DO ICMC-USP

Data de Depósito: 27 de junho de 2014

Assinatura:

\title{
Animação de jatos oscilantes em fluidos viscosos usando SPH em GPU
}

\author{
Luiz Fernando de Souza Andrade
}

Orientador: Prof. Dr. Afonso Paiva Neto

Dissertação apresentada ao Instituto de Ciências Matemáticas e de Computação - ICMC-USP, como parte dos requisitos para obtenção do título de Mestre em Ciências - Ciências de Computação e Matemática Computacional. VERSÃO REVISADA

USP - São Carlos

Junho de 2014 
Ficha catalográfica elaborada pela Biblioteca Prof. Achille Bassi e Seção Técnica de Informática, ICMC/USP, com os dados fornecidos pelo(a) autor(a)

Andrade, Luiz Fernando de Souza
Animação de jatos oscilantes em fluidos viscosos
usando SPH em GPU / Luiz Fernando de Souza Andrade;
orientador Afonso Paiva Neto. -- São Carlos, 2014.
60 p.
Dissertação (Mestrado - Programa de Pós-Graduação
em Ciências de Computaço e Matemática
Computacional) -- Instituto de Ciências Matemáticas
e de Computação, Universidade de São Paulo, 2014.
1. smoothed particle hydrodynamics. 2. jatos
oscilantes. 3. animação computacional. 4. computação
gráfica. 5. mecânica dos fluidos computacional. I.
Neto, Afonso Paiva, orient. II. Título.




\title{
Resumo
}

\begin{abstract}
$\mathcal{N}$ os últimos anos, o estudo de métodos de animação de escoamento de fluidos tem sido uma área de intensa pesquisa em Computação Gráfica. O principal objetivo desse projeto é desenvolver novas técnicas em GPGPU baseadas na arquitetura CUDA para simular o escoamento de fluidos não-newtonianos, tais como fluidos viscoplásticos e viscoelásticos. Ao invés dos tradicionais métodos com malha - diferenças finitas e elementos finitos, essas técnicas são baseadas em uma discretização lagrangeana das equações de governo desses fluidos através do método sem malha conhecido como SPH (Smoothed Particle Hydrodynamics).
\end{abstract}





\section{Abstract}

$I$ $\mathrm{n}$ recent years, the study of methods of animating fluid flow has been an area of intense research in Computer Graphics. The main objective of this project is to develop new techniques based on the CUDA GPGPU architecture to simulate the flow of non-Newtonian fluids, such as viscoelastic and viscoplastic fluids. Instead of traditional methods with mesh - finite differences and finite elements, these techniques are based on a Lagrangian discretization of the governing equations of these fluids through the mesh free method known as SPH (Smoothed Particle Hydrodynamics). 



\section{Sumário}

Resumo ....................... $\mathrm{i}$

Abstract ...............................

Sumário ...................... . .

Lista de Figuras . . . . . . . . . . . . . . . . . vii

Lista de Tabelas ..................... . . . . . . . . . . . . . .

Lista de Algoritmos .................. . . xi

1 Introdução 1

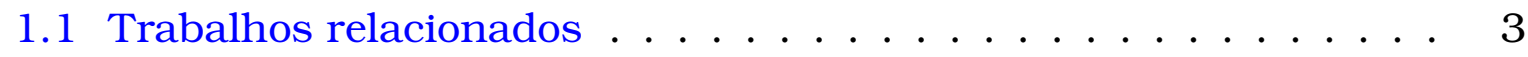

1.2 Objetivos e Contribuições . . . . . . . . . . . . . . . 5

1.3 Organização do texto ..................... 5

2 Mecância dos fluidos computacional com SPH $\quad 7$

2.1 Equações governantes de fluidos newtonianos na forma lagran-

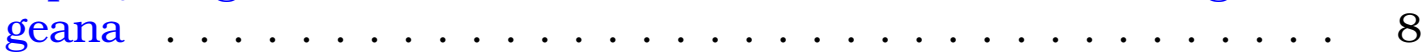

$2.2 \mathrm{O}$ método $\mathrm{SPH} \ldots \ldots \ldots$. . . . . . . . . . . . . 9

2.2.1 Visão geral do método $\mathrm{SPH}$. . . . . . . . . . . . . . . 9

2.2.2 Aproximação por Partículas ............ . 10

2.2 .3 Núcleos $\mathrm{SPH}$. . . . . . . . . . . . . . . . 11

2.2.4 Fluidos com SPH . . . . . . . . . . . . . . . 14

2.2.5 Núcleos SPH especializados . . . . . . . . . . 16

3 Jato oscilante com SPH $\quad 17$

3.1 Fluidos newtonianos e viscosidade . . . . . . . . . . . . 17

3.2 Fluidos não-newtonianos . . . . . . . . . . . . . 18

3.2.1 Viscosidade dependente da tensão de cisalhamento . . . . 18

3.3 Modelo de Cross . . . . . . . . . . . . . . . . . . . 19

3.4 Discretização SPH do modelo de Cross . . . . . . . . . . . . . 19

3.5 Jato oscilante . . . . . . . . . . . . . . . . 20

4 Aspectos numéricos e computacionais 21

4.1 Integração temporal . . . . . . . . . . . . . . . 21

4.1.1 Método de Euler . . . . . . . . . . . . . . . . 22

4.1 .2 Método leap-frog ................ 23

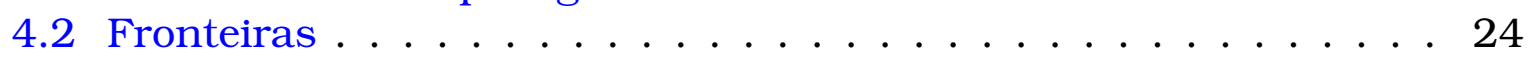


4.3 Particulas vizinhas . . . . . . . . . . . . . . . . 26

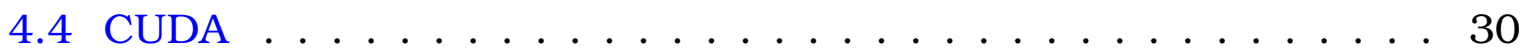

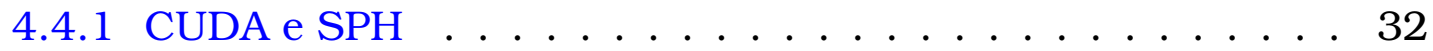

4.5 Implementação SPH em CUDA . . . . . . . . . . . . . . 36

4.5.1 Algoritmo SPH paralelo . . . . . . . . . . . . . . 37

4.5.2 Modelo SPH simples . . . . . . . . . . . . . . . . . . 38

4.5 .3 Modelo SPH viscoso . . . . . . . . . . . . . . . . 38

4.6 Emissão de partículas . . . . . . . . . . . . . . . . . . 39

5 Resultados 41

5.1 CPU x GPU . . . . . . . . . . . . . . . . . . . 42

5.1 .1 Modelo simples . . . . . . . . . . . . . . . . . . 42

5.1 .2 Modelo viscoso . . . . . . . . . . . . . . . . . . 43

5.1.3 Modelo simples X Modelo viscoso . . . . . . . . . . . . 43

5.1 .4 Speedup . . . . . . . . . . . . . . . . 44

5.2 Jato oscilante . . . . . . . . . . . . . . . . . . . 45

6 Conclusão $\quad 55$

6.1 Desempenho . . . . . . . . . . . . . . . . 55

6.2 Trabalhos Futuros . . . . . . . . . . . . . . . 56

$\begin{array}{ll}\text { Referências Bibliográficas } & 60\end{array}$ 


\section{Lista de Figuras}

1.1 Etapas da simulação do escoamento. Imagem retirada de Goktekin et al. (2004). . . . . . . . . . . . . . . . . 3

1.2 Etapas da simulação de acordo com o passo de tempo. Imagem retirada de Rafiee et al. (2007). . . . . . . . . . . . . . . . . . 4

1.3 Etapas da simulação. Imagem retirada de Batty e Bridson (2008). 4

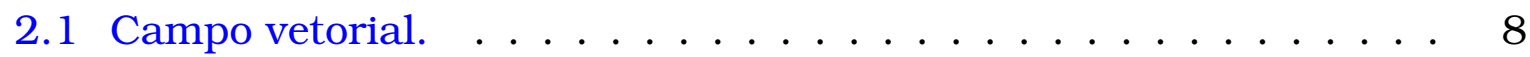

2.2 Domínio de influência. . . . . . . . . . . . . . . 11

2.3 Núcleo SPH gaussiano (azul) com suas derivadas de primeira (vermelho) e segunda (verde) ordem. (Gingold e Monaghan (1977b)) 12

4.1 Representação dos saltos em leap-frog. . . . . . . . . . . . . . . 23

4.2 Fronteiras por partículas fantasmas dispersas . . . . . . . . . 24

4.3 Fronteiras por partículas fantasmas uniformes . . . . . . . . 25

4.4 Colisão partícula $\mathrm{x}$ triângulo. . . . . . . . . . . . . 25

4.5 Grade regular num espaço bi-dimensional. . . . . . . . . . . . . 28

4.6 Guadtree num espaço bi-dimensional. . . . . . . . . . . . . 29

4.7 Pilha de aplicação CUDA. . . . . . . . . . . . . . . . . . . . . . . . . . . . . . . . . .

4.8 Modelo de memória da CUDA. . . . . . . . . . . . . . . 33

4.9 Estrutura de armazenamento não alinhada e estrutura alinhada a 16 bytes ...................... . . . 34

4.10 Ordenação das partículas de acordo com a sua posição na grade. 35

5.1 Comparação com a realidade. . . . . . . . . . . . . 41

5.2 Modelo simples em GPU. . . . . . . . . . . . . . . . . . . . . . . . . . . . . . . . 43

5.3 Modelo simples em CPU. . . . . . . . . . . . . . . . . . . 43

5.4 Análise computacional do modelo simples em relação aos melhores resultados de CPU e GPU. . . . . . . . . . . . . . . . . . . 44

5.5 Modelo viscoso GPU . . . . . . . . . . . . . . . . . . . 45

5.6 Modelo viscoso CPU . . . . . . . . . . . . . . . . . . 46

5.7 Viscoso CPU x GPU . . . . . . . . . . . . . . . . . . . . 47

5.8 Modelo simples X Modelo viscoso CPU . . . . . . . . . . . . . . 47

5.9 Modelo simples X Modelo viscoso GPU . . . . . . . . . . . . . . 48 
5.10 Passos da simulação de jato oscilante com a superfície livre sendo representada de forma implícita. . . . . . . . . . . . . 48

5.11 Emissor em movimento . . . . . . . . . . . . . . 48

5.12 Passos simulação jato oscilante. . . . . . . . . . . . . . . . . 49

5.13 Passos de simulação do jato oscilante. Emissor retangular . . . . 49

5.14 Passos simulação jato oscilante. Detalhe para o inicio da simulação 50

5.15 Passos da simulação do jato oscilante. Emissor retangular variado o K. . . . . . . . . . . . . . . . . . . 5 51

5. 16 Passos de uma simulação de um torus com variação de parâmetros. 52

5.17 Passo de simulação do jato oscilante representado por particulas. 53

5.18Passo de simulação do jato oscilante representado por particulas. 54 


\section{Lista de Tabelas}

5.1 Speedup CPU(i5 3570) x GPU(GTX 580) . . . . . . . . . . . . . 44 



\section{Lista de Algoritmos}

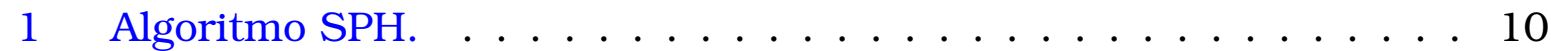

2 Algoritmo de utilização da grade regular virtual. . . . . . . . . . . 36

3 Algoritmo de atravessamento de uma célula da grade. . . . . . . . 36

4 Algoritmo SPH paralelo. . . . . . . . . . . . . . . . . . 38

5 Algoritmo SPH Viscoso paralelo. . . . . . . . . . . . . . . . 39 



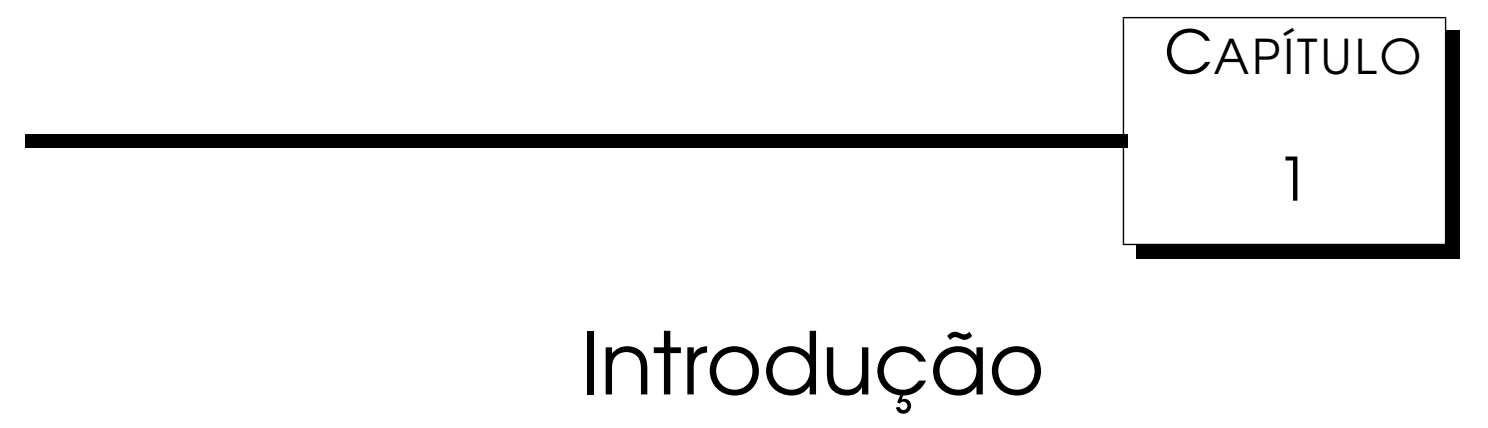

$\mathcal{A}$ computação gráfica é a área da computação dedicada a geração de imagens através do computador (Nogueira et al. (2004)). Seu surgimento partiu da necessidade humana de visualizar os dados que processamos em suas diversas aplicações, entre as quais destacam-se jogos, cinema, design visual e engenharia.

Na Computação Gráfica podemos observar grandes interações com outras áreas da ciência como a física, que com seus conceitos de ótica permitiu a elaboração de modelos de cores e iluminação e modelos físicos para simulação numérica de fenômenos. Usa-se da matemática conceitos de álgebra linear, trigonometria e cálculo numérico.

Uma aplicação gráfica é um programa ou um sistema que permite a geração de uma determinada apresentação visual, onde pode ser composta de recursos 2D e/ou 3D. Essas aplicações em geral possuem interação humanocomputador que permite geração interativa de uma apresentação gráfica.

Nos últimos anos em Computação Gráfica foram desenvolvidas várias técnicas de animação de objetos como corpos rígidos, água, fumaça, cabelo e tecido (Müller et al. (2003)). Essas técnicas se concentram em modelos físicos simplificados como fluidos newtonianos monofásicos ou de sólidos ideais - sólidos que não sofrem nenhuma deformação plástica.

Líquidos viscosos fazem parte da nossa vida cotidiana, com exemplos domésticos tais como mel, xarope, xampu e ketchup até fenômenos naturais como lava, argila e areia movediça. A característica marcante desses líquidos 
é a sua resistência ao escoamento que resulta em um movimento lento do fluido, isto é, alta dissipação da velocidade do escoamento do fluido. Guando um fluido viscoso é derramado sobre uma superfície, ele geralmente começa a se espiralar e dobrar em si mesmo produzindo uma superfície interfacial complexa e rica em detalhes, esse efeito é chamado de jato oscilante. Nessa dissertação, propomos um novo método de animação visualmente realística de escoamento de fluidos que possuem o comportamento físico dos jatos oscilantes, caracterizados principalmente pela viscosidade, tais como os fluidos viscoplásticos e viscoelásticos. Em particular, esses fluidos pertencem a uma rica classe de fluidos conhecida como fluidos não-newtonianos.

Os fluidos não-newtonianos são estudados extensivamente em mecânica dos fluidos computacional, e o estudo deles é conhecido como reologia computacional (Owens e Phillips (2002)). Nesse projeto, ao contrário dos tradicionais métodos numéricos que utilizam malha em simulações computacionais de escoamento de fluidos (diferenças finitas e elementos finitos), discretizamos o fluido através de um sistema de partículas baseado em um método numérico puramente lagrangeano conhecido como Smoothed Particle Hydrodynamics (SPH) (Müller et al. (2003)).

Os métodos sem malha começaram com o método SPH proposto por Gingold e Monaghan (1977b) e Lucy (1977b), originalmente inventado para modelar fenômenos astrofísicos. A principal idéia nessa classe de métodos é obter soluções precisas e numericamente estáveis para equações diferenciais parciais através de uma discretização espacial dada por um conjunto de partículas sem o uso de qualquer tipo de informação topológica (conectividade) entre as partículas. Nesse caso, cada partícula pode representar diretamente um objeto físico ou uma parte de todo o sistema contínuo.

Apesar de darmos enfoque para o uso de SPH na simulação de fluidos e da sua origem na astrofisica, ele pode ser aplicado em outras áreas como geologia e engenharia e engloba diversas áreas de conhecimento, como equações diferenciais parciais, estruturas de dados, métodos de ordenação e busca, representação de superfícies implícitas discretas, rendering, entre outras. Uma das vantagens do método SPH é a adaptabilidade do método, que é capaz de acoplar novas características ao mesmo problema, como por exemplo, integrar fluidos multifásicos à uma simulação de fluidos apenas adicionando forças ao algoritmo.

O SPH é um método sem malha, ou seja, não é usada nenhuma malha que forneça conectividade entre as partículas. Métodos com malha requerem um 
esforço computacional maior pois requerem um pré-processamento da malha e a sua manutenção no decorrer da simulação, enquanto métodos sem malha requerem apenas que haja uma forma eficiente de detecção de vizinhança.

A deteç̧ão de vizinhança é um ponto critico nos métodos sem malha, pois a eficiência do cálculo das interações entre as partículas depende da eficiência da detecção de quais partículas são vizinhas, se a detecção de vizinhança contiver falhas ou for lenta, o método será ineficiente e apresentará instabilidades.

Com um método detecção de vizinhança eficiente, o método SPH se resume a, em cada iteração, atualizar a densidade, a pressão, a aceleração e definir a nova posição de cada partícula do sistema. Como veremos adiante, para definir a nova posição de uma partícula no espaço é feita uma integração temporal de acordo com o intervalo de tempo entre uma iteração e outra, respeitando condições de fronteira que verificam se uma partícula não se desprendeu do espaço da simulação ou se não invadiu o espaço de outro corpo. Existem diferentes técnicas de integração temporal e de verificação de condições de fronteira na literatura (Paiva et al. (2009b); Gingold e Monaghan (1977b); Monaghan e Kovharyan (1995); Morris (1996); Müller et al. (2003)).

\subsection{Trabalhos relacionados}

Nesta revisão bibliográfica podemos observar que existem poucos trabalhos na literatura tanto de animação computacional e de SPH que propõem métodos de simulação de escoamento de fluidos viscosos com efeito de jatos oscilantes. Isso se deve não só a complexidade de modelar computacionalmente as equações constitutivas desses fluidos, mas também a representação da superfície livre que representa a interface entre o líquido e o ar.

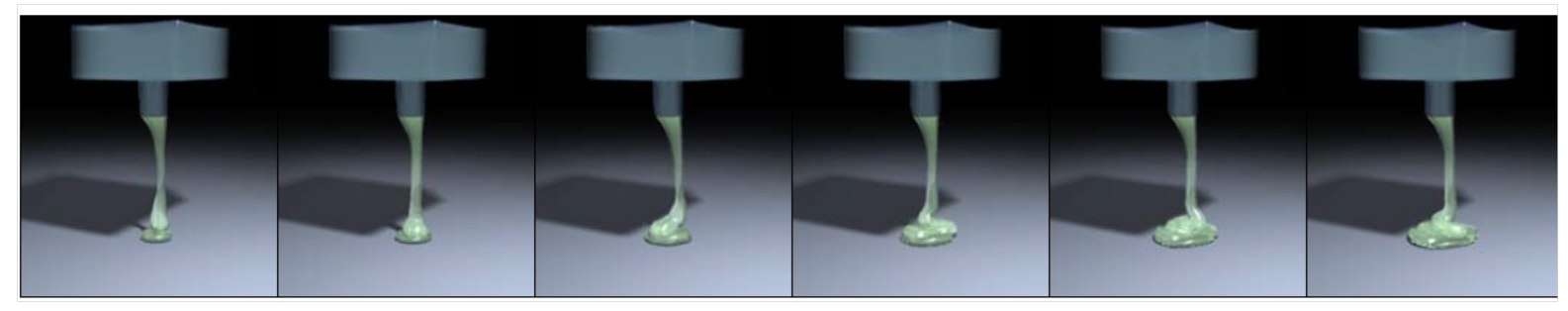

Figura 1.1: Etapas da simulação do escoamento. Imagem retirada de Goktekin et al. (2004).

O primeiro trabalho em animação surgiu em 2004, onde Goktekin et al. (2004) propuseram um método utilizando uma malha (grade) euleriana para 
simular fluidos viscoelásticos baseado no modelo linear de Maxwell (veja Figura 1.1).

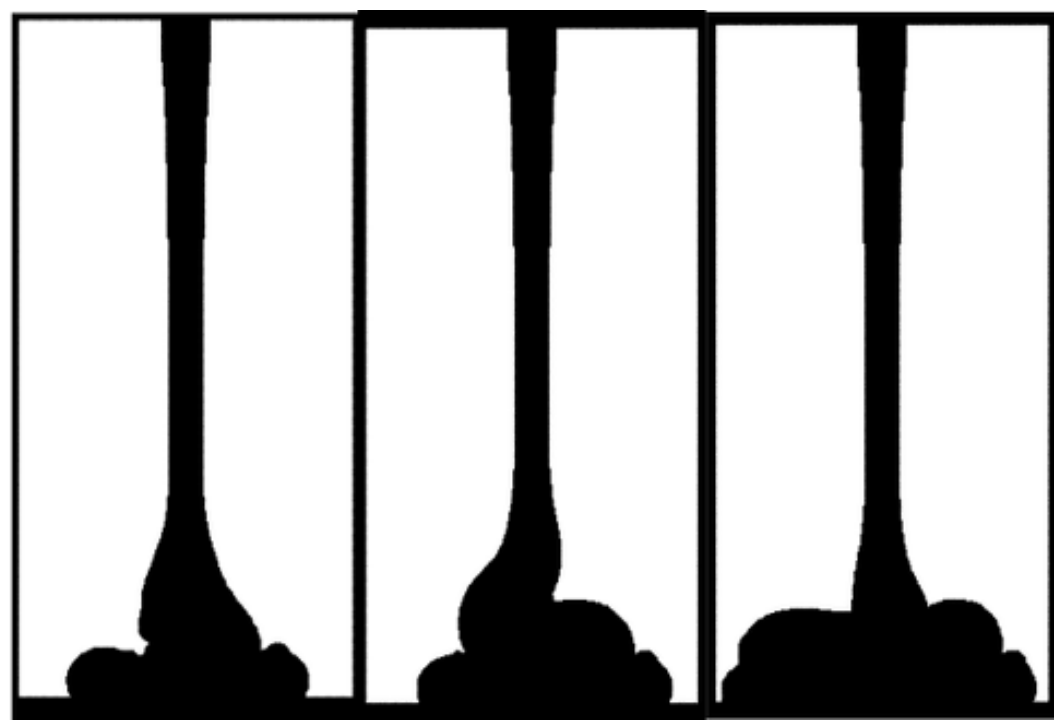

Figura 1.2: Etapas da simulação de acordo com o passo de tempo. Imagem retirada de Rafiee et al. (2007).

O método SPH foi usado por Rafiee et al. (2007) para simular escoamentos $2 \mathrm{D}$ de fluidos viscoelásticos incompressíveis. Nesse trabalho, os autores utilizaram uma versão incompressivel do SPH usando método da projeção para o cálculo da pressão (veja Figura 1.2).

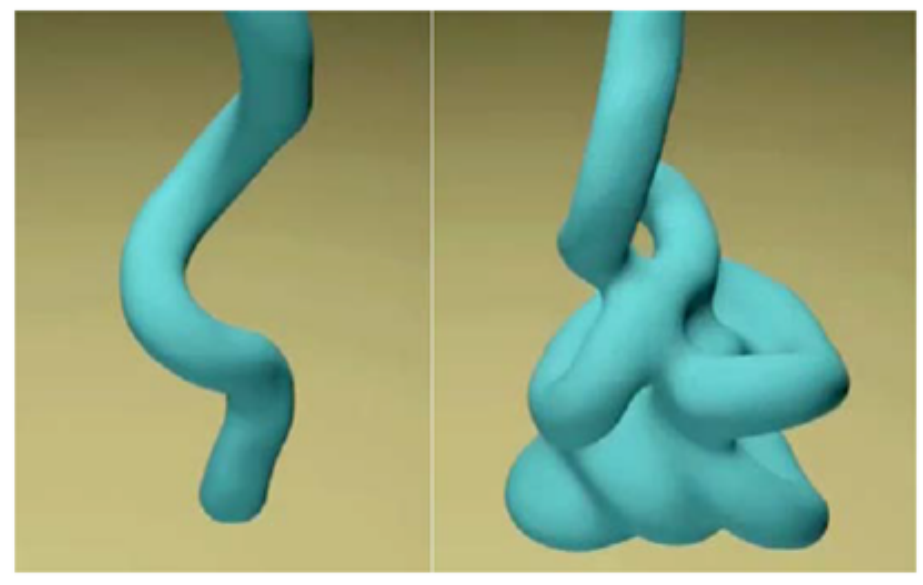

Figura 1.3: Etapas da simulação. Imagem retirada de Batty e Bridson (2008).

Mais tarde, Batty e Bridson (2008) criariam um método euleriano implícito baseado em princípios variacionais. Entretanto, a representação implícita que os autores utilizaram não é capaz de reproduzir as "características afiadas" típicas em simulações desta natureza (veja Figura 1.3). 
Recentemente em físca computacional, Xu et al. (2013a) utilizaram a versão quase incompressivel do método SPH para simular escoamento 3D de jatos oscilantes. Nesse trabalho, os autores utilizaram o modelo de Cross como modelo constitutivo do fluido não-newtoniano.

\subsection{Objetivos e Contribuições}

O método SPH é bastante popular na industria do entretenimento devido ao seu sucesso em aplicações de animação computacional de fenômenos físicos, principalmente em simulação de fluidos. Essa massificação de seu uso pelos designers gráficos se deve a softwares que oferecem uma interatividade ao designer como o Real Flow ${ }^{1}$. O principal objetivo dessa dissertação é propor um novo sistema de animação de escoamento de fluidos viscosos usando o método SPH que seja capaz de reproduzir de forma visualmente plausível o efeito de jato oscilante de forma eficaz. Para alcançar tais objetivos vamos utilizar técnicas de GPGPU baseadas na arquitetura CUDA. Além disso, para nosso conhecimento, esse trabalho é o primeiro na literatura de animação computacional a simular jatos oscilantes usando métodos sem malha.

\subsection{Organização do texto}

O texto está organizado da seguinte forma. O Capítulo 2 apresenta os conceitos básicos de mecânica dos fluidos e uma breve introdução ao método SPH. O Capítulo 3 fala sobre o modelo reológico adotado e sua discretização SPH. No Capítulo 4 são mostrados os aspectos numéricos e computacionais do trabalho, arquitetura CUDA e suas particularidades. O Capítulo 5 contém os resultados e comparações deste trabalho, finalizando com o Capítulo 6, que traz as conclusões e trabalhos futuros.

${ }^{1}$ http: //www.realflow.com/ 



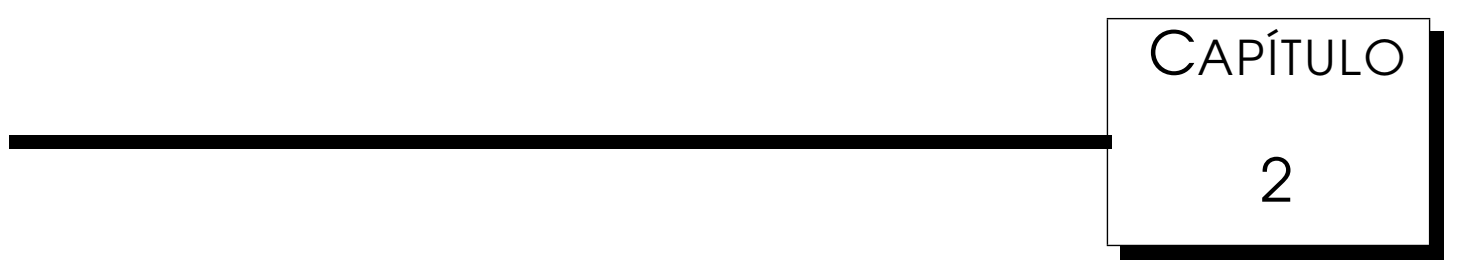

\section{Mecância dos fluidos computacional com SPH}

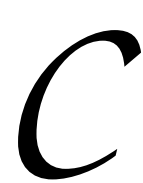

omo visto em Paiva et al. (2009b), as equações de Navier-Stokes são baseadas na segunda Lei de Newton e visam aplicar tal lei à mecânica dos fluidos, tendo em vista que um elemento de fluido sofre ação de forças externas que somadas geram uma força resultante que define a variação no momento desse elemento.

Outras leis físicas compõem as equações de Navier-Stokes, tal como a primeira lei da termodinâmica (conservação da energia) e a lei da conservação da massa. Em termos gerais essas duas leis descrevem que a energia de um elemento é igual a soma do fluxo de energia sobre o elemento e que um fluido tem sua massa mantida durante todo o tempo.

As equações de Navier-Stokes definem a velocidade de um elemento de fluido, ou seja: a taxa de variação da sua posição no espaço de acordo com o tempo. Essas variações da velocidade dos elementos de um fluido podem ser vistos como um campo vetorial de velocidades, onde a velocidade dos elementos aponta na direção e sentido do escoamento do fluido naquele ponto. 


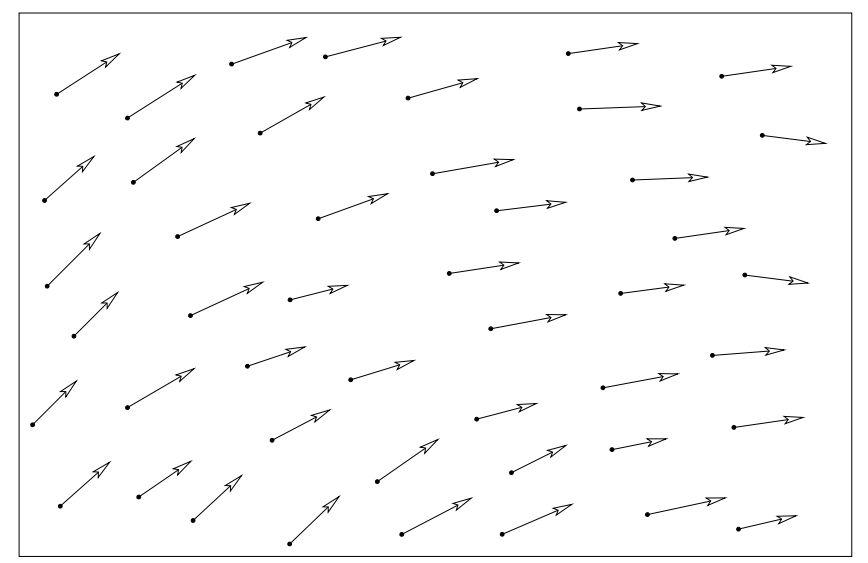

Figura 2.1: Exemplo de um campo vetorial de velocidade, cada ponto representa uma partícula em um espaço bidimensional e os vetores associados representam sua velocidade (direção, sentido e módulo).

\subsection{Equações governantes de fluidos newtonianos na forma lagrangeana}

Como descrito em Paiva et al. (2009b), existem duas formas de interpretar o significado de um "elemento de fluido", a forma euleriana e a lagrangeana. A abordagem lagrangeana considera um elemento de fluido como um elemento livre que se move de acordo com o escoamento, dessa forma o ponto de referencia dos cálculos é móvel como uma partícula que é carregada pela corrente. Para fluidos incompressiveis, as equações de Navier-Stokes na forma lagrangeana são dadas por:

$$
\begin{aligned}
& \frac{\partial \mathbf{v}}{\partial t}=-\frac{1}{\rho} \nabla p+\frac{\mu}{\rho} \nabla^{2} \mathbf{v}+\mathbf{f} \\
& \frac{\partial \rho}{\partial t}=0
\end{aligned}
$$

onde $\mathbf{v}$ é a velocidade de escoamento, $\rho$ é a densidade do fluido, $p$ é a pressão do fluido, $\mu$ é a viscosidade do fluido e f é uma força externa que age sobre o fluido. A equação (2.1a) é conhecida como equação de momento e é deduzida pela segunda lei de Newton, enquanto a equação (2.1b) é chamada de equação da continuidade e trata da conservação de massa.

O método SPH utilizado para o estudo de fluidos é baseado em partículas que representam quantidades infinitesimais de fluido que são vistas como elementos discretos que podem ser tratados sob a abordagem lagrangeana. 


\subsection{O método SPH}

O SPH foi criado para resolver problemas de astrofísica (Lucy, 1977a; Gingold e Monaghan, 1977a), porém foi amplamente estendido para problemas de outra natureza como, por exemplo, os de hidrodinâmica. Na simulação de fluidos, o SPH trata cada elemento de fluido como uma partícula que se comporta de acordo com as equações de Navier-Stokes.

\subsubsection{Visão geral do método SPH}

Apesar de darmos enfoque para o uso de SPH na simulação de fluidos e da sua origem na astrofísica, ele pode ser aplicado em outras áreas como geologia e engenharia e engloba diversas áreas de conhecimento, como equações diferenciais parciais, estruturas de dados, métodos de ordenação e busca, representação de superfícies implícitas discretas, rendering, entre outras. Uma das vantagens do método SPH é a adaptabilidade do método, que é capaz de acoplar novas características ao mesmo problema, como por exemplo, integrar fluidos multifásicos à uma simulação de fluidos apenas adicionando forças ao algoritmo.

O SPH é um método sem malha, ou seja, não é usada nenhuma malha que forneça conectividade entre as partículas. Métodos com malha requerem um esforço computacional maior pois requerem um pré-processamento da malha e a sua manutenção no decorrer da simulação, enquanto métodos sem malha requerem apenas que haja uma forma eficiente de detecção de vizinhança.

A detecção de vizinhança é um ponto critico nos métodos sem malha, pois a eficiência do cálculo das interações entre as partículas depende da eficiência da detecção de quais partículas são vizinhas, se a detecção de vizinhança contiver falhas ou for lenta, o método será ineficiente e apresentará instabilidades.

Com uma detecção de vizinhança eficiente, o método $\mathrm{SPH}$ se resume a, a cada iteração, atualizar a densidade, a pressão, a aceleração e definir a nova posição de cada partícula do sistema. Como veremos adiante, para definir a nova posição de uma partícula no espaço é feita uma integração temporal de acordo com o intervalo de tempo entre uma iteração e outra, respeitando condições de fronteira que verificam se uma partícula não se desprendeu do espaço da simulação ou se não invadiu o espaço de outro corpo. Existem diferentes técnicas de integração temporal e de verificação de condições de fronteira. 
Reunindo os passos citados, temos o algoritmo 1. Nesse algoritmo os cálculos da aceleração e densidade são feitas a partir das equações de Navier-Stokes (2.1a) e (2.1b).

1 Inicialização do sistema;

2 repita

3 Faça a busca de partículas vizinhas;

4 para cada partícula $i$ hacer

\section{fin}

para cada partícula $i$ hacer

Calcule a aceleração;

Calcule a densidade;

fin

para cada partícula $i$ hacer

Atualize $\mathbf{v}_{i}$ e $\rho_{i}$ com o integrador temporal;

Aplique a condição de fronteira;

\section{fin}

Atualize $\Delta t$ de acordo com o integrador temporal usado; tempo $=$ tempo $+\Delta t$

$\mathrm{n}^{0}$ de iterações $=\mathrm{n}^{0}$ de iterações +1 ;

8 até tempo = tempo máximo ou $n^{o}$ de iterações $=n^{o}$ máximo de iterações;

Algoritmo 1: Algoritmo SPH.

Em particular, uma introdução sobre o método SPH pode ser encontrada em Paiva et al. (2009b).

\subsubsection{Aproximação por Partículas}

A base do SPH está na teoria da interpolação. O princípio fundamental é aproximar uma função qualquer $A$ onde, o valor de $A$ no ponto $\mathrm{x} \in \mathbb{R}^{d}$ é dado pela convolução de $A$ com a função generalizada delta de Dirac $\delta$ :

$$
A(\mathbf{x})=\int A\left(\mathbf{x}^{\prime}\right) \delta\left(\left\|\mathbf{x}-\mathbf{x}^{\prime}\right\|\right) d \mathbf{x}^{\prime}
$$

O delta de Dirac pode ser interpretado como uma distribuição $\delta(x)$ onde:

$$
\delta(x)=0, \text { se } x \neq 0
$$

e satisfazendo

$$
\int_{\mathbb{R}} \delta(x) d x=1
$$


Temos que a função $\delta$ é aproximada por uma função suave $W_{h}$ chamada núcleo, onde $h$ é o comprimento suave e controla o domínio de influência $\Omega \subseteq$ $\mathbb{R}^{d}$ representado na Figura 2.2. Então, a equação (2.2) pode ser aproximada como:

$$
A(\mathbf{x}) \approx \int_{\Omega} A\left(x^{\prime}\right) W_{h}\left(\left\|\mathbf{x}-\mathbf{x}^{\prime}\right\|\right) d \mathbf{x}^{\prime} .
$$

Na forma discreta, podemos escrever a aproximação de $A(\mathrm{x})$ como:

$$
A\left(\mathbf{x}_{i}\right) \approx \sum_{j \in N_{i}} V_{j} A\left(\mathbf{r}_{j}\right) W_{h}\left(\left\|\mathbf{x}_{i j}\right\|\right),
$$

onde $\mathbf{x}_{i j}=\mathbf{x}_{i}-\mathbf{x}_{j}, V_{j}$ é o volume da partícula $j$ e $N_{i}$ se refere a vizinhança da partícula $i$.

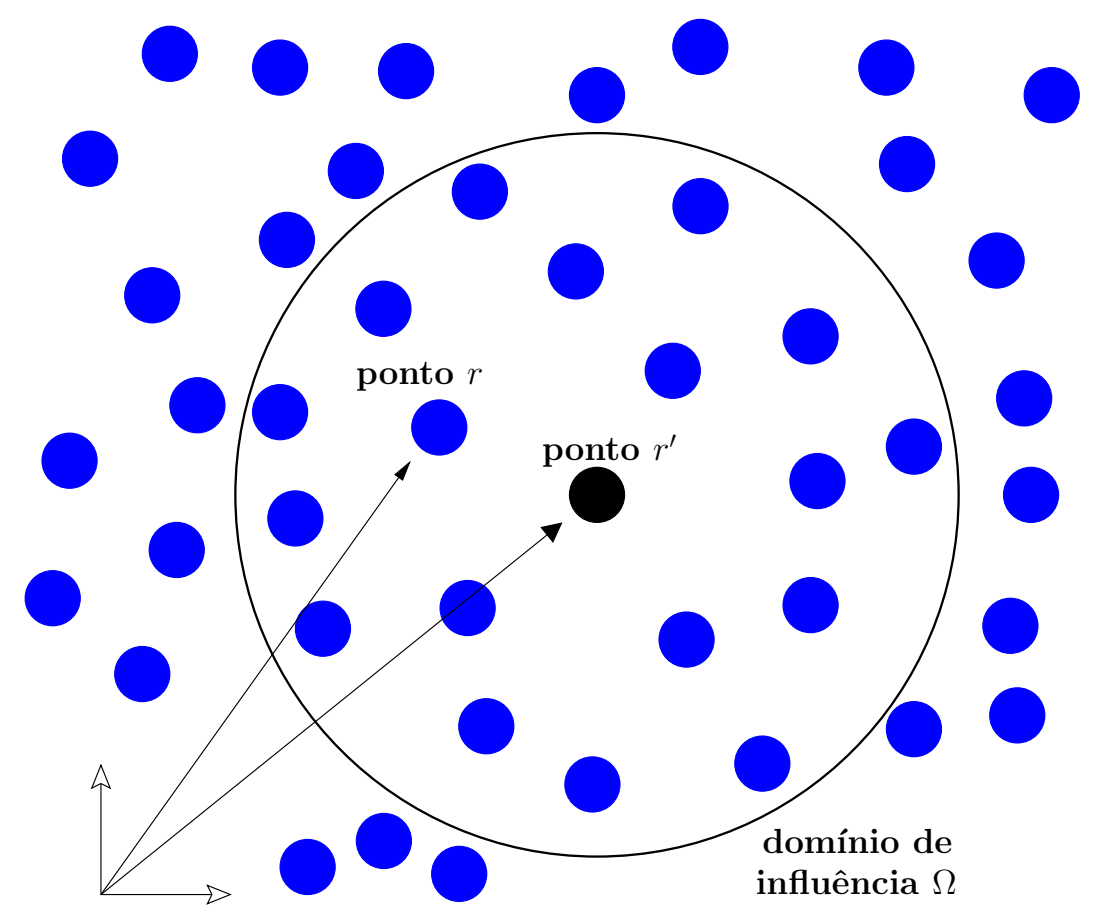

Figura 2.2: Domínio de influência.

\subsubsection{Núcleos SPH}

A escolha do núcleo SPH pode ser importante para vários aspectos de uma simulação. A precisão numérica é altamente dependente do núcleo SPH e a pesquisa mostrou que certos núcleos oferecem melhores resultados do que outros (Crespo (2008)). A eficiência computacional de um núcleo também pode ser significativa, núcleos de alta ordem podem levar a um custo computacional 
significativamente maior, o que pode impor um limite para outros parâmetros da simulação e assim negando as vantagens. Vários núcleos foram desenvolvidos ao longo da história do $\mathrm{SPH}$, vamos discutir algum deles.

\section{Gaussiano}

A função gaussiana é uma escolha óbvia para um núcleo, é suficientemente suave, mesmo para altas ordens de derivação, contudo carrega um grande custo computacional. Ela também não tem suporte compacto, uma vez que não atinge zero para $q>2$, o que significa que teoricamente teria que avaliar todas as partículas da simulação.

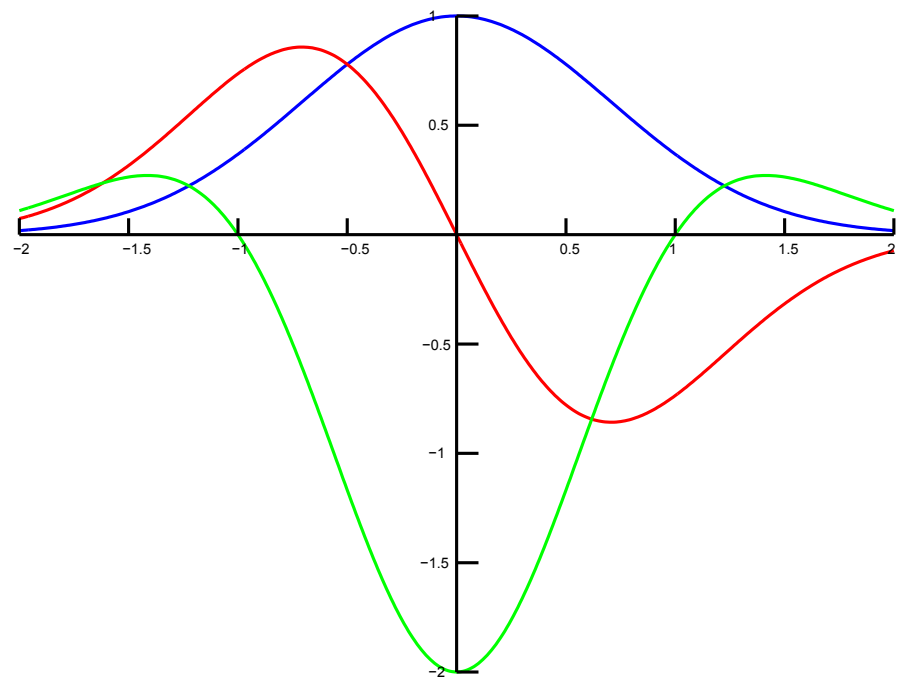

Figura 2.3: Núcleo SPH gaussiano (azul) com suas derivadas de primeira (vermelho) e segunda (verde) ordem. (Gingold e Monaghan (1977b))

$$
W_{\text {gaussian }}\left(\left\|\mathbf{x}_{i j}\right\|, h\right)=\alpha_{D} \exp \left(-q^{2}\right) \quad 0 \leq q \leq 2,
$$

onde $q=\frac{\left\|\mathbf{x}_{i j}\right\|}{h}$ e $\alpha_{D}$ é um fator dimensional que vale $\frac{120}{\sqrt{\pi}}$ em $1 \mathrm{D}, \frac{1}{\pi h^{2}}$ em $2 \mathrm{D}$ e $\frac{1}{\pi^{3 / 2} h^{3}}$ em 3D.

Spline Cúbico

O núcleo spline cúbico é o núcleo mais comum utilizado na literatura SPH. Foi inicialmente introduzido por Monaghan e Latanzio (1985) e oferece um compromisso razoável entre custo e precisão computacional. Além disso, tem suporte compacto. O problema com este núcleo é que a segunda derivada não 
é suave, tornando-o inadequado para utilização do cálculo do laplaciano.

$$
W_{\text {cubic }}\left(\left\|\mathbf{x}_{i j}\right\|, h\right)=\alpha_{D}\left\{\begin{array}{rc}
1-\frac{3}{2} q^{2}+\frac{3}{4} q^{3} & 0 \leq q \leq 1 \\
\frac{1}{4}(2-q)^{3} & 1 \leq q \leq 2, \\
0 & q \geq 2
\end{array}\right.
$$

onde $q=\frac{\left\|\mathbf{x}_{i j}\right\|}{h}$ e $\alpha_{D}$ é um fator dimensional que vale $\frac{10}{7 \pi h^{2}}$ em 2D e $\frac{1}{\pi h^{3}}$ em 3D.

Spline Quíntico

O núcleo spline quíntico foi usado por Morris et al. (1997) para simular fluidos incompressíveis com baixo numero de Reynolds. Infelizmente este núcleo é computacionalmente caro.

$$
W_{\text {quintic }}\left(\left\|\mathbf{x}_{i j}\right\|, h\right)=\alpha_{D}\left\{\begin{array}{rc}
(3-q)^{5}-6(2-q)^{5}+15(1-q)^{5} & 0 \leq q<1 \\
(3-q)^{5}-6(2-q)^{5} & 1 \leq q<2 \\
(3-q)^{5} & 2 \leq q \leq 3 \\
0 & q \geq 3
\end{array}\right.
$$

onde $q=\frac{\left\|\mathbf{x}_{i j}\right\|}{h}$ e $\alpha_{D}$ é um fator dimensional que vale $\frac{120}{h}$ em 1D, $\frac{7}{478 \pi h^{2}}$ em 2D e $\frac{3}{359 \pi h^{3}}$ em 3D.

\section{Quadrático}

Este núcleo impede agrupamento de partículas em problemas de compressão. Isto é porque a derivada sempre aumenta a medida que as partículas se movem para mais perto e sempre diminui quando elas se afastam (Crespo, 2008).

$$
W_{\text {quadratic }}\left(\left\|\mathbf{x}_{i j}\right\|, h\right)=\alpha_{D}\left\{\frac{3}{16} q^{2}-\frac{3}{4} q+\frac{3}{4} \quad 0 \leq q \leq 2,\right.
$$

onde $q=\frac{\left\|\mathbf{x}_{i}\right\|}{h}$ e $\alpha_{D}$ é um fator dimensional que vale $\frac{2}{\pi h^{2}}$ em 2D e $\frac{51}{4 \pi h^{3}}$ em 3D.

Wendland

Este núcleo Wendland (Wendland, 2006, 1995) foi encontrado para ter a melhor relação entre precisão e custo computacional. Normalmente, quanto maior a ordem do núcleo, maior a precisão do esquema SPH.

$$
W_{\text {Wendland }}\left(\left\|\mathbf{x}_{i j}\right\|, h\right)=\alpha_{D}\left\{\left(1-\frac{q}{2}\right)^{4}(2 q+1) \quad 0 \leq q \leq 2,\right.
$$

onde $q=\frac{\left\|\mathbf{x}_{i j}\right\|}{h}$ e $\alpha_{D}$ é um fator dimensional que vale $\frac{7}{4 \pi h^{2}}$ em 2D e $\frac{7}{8 \pi h^{3}}$ em 3D. 


\section{Quártico}

Este núcleo definido por Liu et al. (2003) satisfaz a condição de normalização e tanto a função e sua primeira derivada tem suporte compacto. É similar a (2.8) mas tem várias vantagens em relação a ele, sendo mais estável e que não é por partes, o que significa que não há necessidade de ramificação na avaliação do mesmo.

$$
W_{\text {quartic }}\left(\left\|\mathbf{x}_{i j}\right\|, h\right)=\alpha_{D}\left\{\begin{array}{rc}
\frac{2}{3}-\frac{9}{8} q^{2}+\frac{19}{24} q^{3}-\frac{5}{32} q^{4} & 0 \leq q \leq 2 \\
0 & q \geq 2
\end{array},\right.
$$

onde $q=\frac{\left\|\mathbf{x}_{i j}\right\|}{h}$ e $\alpha_{D}$ é um fator dimensional que vale $\frac{1}{h}$ em $1 \mathrm{D}, \frac{15}{7 \pi h^{2}}$ em $2 \mathrm{D}$ e $\frac{315}{208 \pi h^{3}}$ em 3D.

\subsubsection{Fluidos com SPH}

Nessa seção são apresentados os cálculos usados para atualizar as propriedades do fluido, assumindo ele representado por um sistema de partículas onde cada uma dessas partículas possui propriedades como velocidade, pressão, densidade, viscosidade, etc. Lembrando que a aceleração de uma partícula é dada pela equação 2.1a, precisamos calcular a força que a pressão e a viscosidade do fluido exercem sobre cada partícula, além de forças externas como a gravidade. O conteúdo dessa seção foi escrito de acordo com Müller et al. (2003).

\section{Cálculo da densidade}

A atualização da densidade depende apenas da massa da partícula, logo ela pode ser calculada antes das outras propriedades. A densidade $\rho_{i}$ de uma partícula $i$ pode ser calculada usando a equação:

$$
\rho_{i}=\sum_{j \in N_{i}} m_{j} W\left(\left\|\mathbf{x}_{i j}\right\|, h\right)
$$

\section{Cálculo da pressão}

Em SPH fluidos incompressíveis são aproximados por fluidos quase incompressiveis através de uma equação de estado para a pressão. Dessa forma, a pressão $p_{i}$ de uma partícula $i$ é calculada usando uma adaptação da lei dos 
gases perfeitos observada em Desbrun e Cani (1996):

$$
p_{i}=k\left(\rho_{i}-\rho_{0}\right) \text {, }
$$

onde $\rho_{0}$ é a densidade de repouso do fluido e $k$ é uma constante dos gases. Além disso, quanto menor for o valor de $k$ mais compressível será o fluido. $\mathrm{Na}$ simulação de fluidos (quase) incompressíveis ou fracamente compressíveis, uma boa escolha para a constante dos gases é $k=c^{2}$ onde $c$ é a velocidade do som de acordo com Morris et al. (1997).

A força de pressão é a força exercida pelos elementos de fluido nos seus vizinhos devido à pressão do fluido e que tende a atrair partículas que estão afastadas e repelir partículas que estão próximas demais umas das outras. Sabendo a pressão de cada partícula 2.14, podemos fazer o cálculo da força de pressão, ou gradiente de pressão, usando a equação:

$$
f_{i}^{\text {pressão }}=-\frac{1}{\rho_{i}} \nabla p_{i}=-\sum_{j \in N_{i}} m_{j} \frac{p_{i}+p_{j}}{2 \rho_{j}} \nabla W\left(\left\|\mathbf{x}_{i j}\right\|, h\right) .
$$

Forças viscosas

Um fluido é uma substância que não pode resistir a tensões de cisalhamento e consequentemente irá se deformar e fluir. A força interna do fluido que representa resistência a esse fenômeno é a viscosidade. A força exercida nas partículas em uma simulação SPH pode ser calculada da seguinte forma:

$$
f_{i}^{\text {viscosidade }}=\frac{\mu}{\rho_{i}} \nabla^{2} \mathbf{v}_{i}=\frac{\mu}{\rho_{i}} \sum_{j \in N_{i}} m_{j} \frac{\mathbf{v}_{i j}}{\rho_{j}} \nabla^{2} W\left(\left\|\mathbf{x}_{i j}\right\|, h\right)
$$

onde $\mu$ é o coeficiente de viscosidade e $\mathbf{v}_{i j}=\mathbf{v}_{i}-\mathbf{v}_{j}$.

Fluidos com um coeficiente de viscosidade maior tendem a ser mais coesos e a se moverem mais devagar que fluidos com menor viscosidade.

\section{Cálculo da aceleração}

Finalmente, a aceleração $a_{i}$ de uma partícula de fluido $i$ é dada pela razão entre a soma das forças exercidas pela pressão, viscosidade e externas como a força gravitacional pela sua própria densidade $\rho_{i}$ :

$$
\mathbf{a}_{i}=\frac{1}{\rho_{i}} f_{i}^{\text {pressão }}+\frac{1}{\rho_{i}} f_{i}^{\text {viscosidade }}+\mathbf{g} .
$$




\subsubsection{Núcleos SPH especializados}

Müller et al. (2003) criaram núcleos especializados, com o intuito de aumentar o desempenho e estabilidade da simulação em animações de escoamento de fluido. Estes núcleos são geralmente não tão precisos e podem introduzir erros na simulação, mas podem melhorar significativamente a estabilidade global do sistema.

\section{Densidade}

O núcleo chamado por poly6 é uma spline de grau 6 e é utilizado no cálculo da densidade. Este núcleo tem um desempenho altamente eficiente, já que não é polinômio por partes.

$$
W_{\text {poly } 6}\left(\left\|\mathbf{x}_{i j}\right\|, h\right)=\frac{315}{64 \pi h^{9}}\left\{\begin{array}{r}
\left(h^{2}-\left\|\mathbf{x}_{i j}\right\|^{2}\right)^{3} \\
0 \leq\left\|\mathbf{x}_{i j}\right\| \leq h \\
0 \quad \text { caso contrário }
\end{array},\right.
$$

Pressão

A razão do núcleo (2.18) não ser utilizado para pressão se deve ao fato da sua derivada se anular quando se aproxima de zero. Isto significa que partículas em áreas de alta pressão não irão se repelir, o que leva a uma aglomeração indesejada de partículas. A fim de evitar tais problemas Müller et al. (2003) criaram um núcleo chamado de spiky.

$$
W_{\text {spiky }}\left(\left\|\mathbf{x}_{i j}\right\|, h\right)=\frac{15}{\pi h^{6}}\left\{\begin{array}{r}
\left(h-\left\|\mathbf{x}_{i j}\right\|\right)^{3} \\
0 \leq\left\|\mathbf{x}_{i j}\right\| \leq h \\
0 \quad \text { caso contrário }
\end{array},\right.
$$

Viscosidade

A viscosidade pode ser pensada como a suavização do campo de velocidade. No contexto de simulação de escoamento de fluidos a suavização de velocidades deve levar a redução de sua velocidade relativa por dissipação. No entanto, para partículas próximas o laplaciano de (2.18) é negativo, levando a um aumento relativo de suas velocidades.Por estas razões, este núcleo foi introduzido para o cálculo das forças viscosas.

$$
W_{\text {viscous }}\left(\left\|\mathbf{x}_{i j}\right\|, h\right)=\frac{15}{2 \pi h^{3}}\left\{\begin{array}{r}
-\frac{\left\|\mathbf{x}_{i j}\right\|^{3}}{2 h^{3}}+\frac{\left\|\mathbf{x}_{i j}\right\|^{2}}{h^{2}}+\frac{h}{2\left\|\mathbf{x}_{i j}\right\|}-1 \\
0 \quad \text { caso contrário }
\end{array}\right.
$$




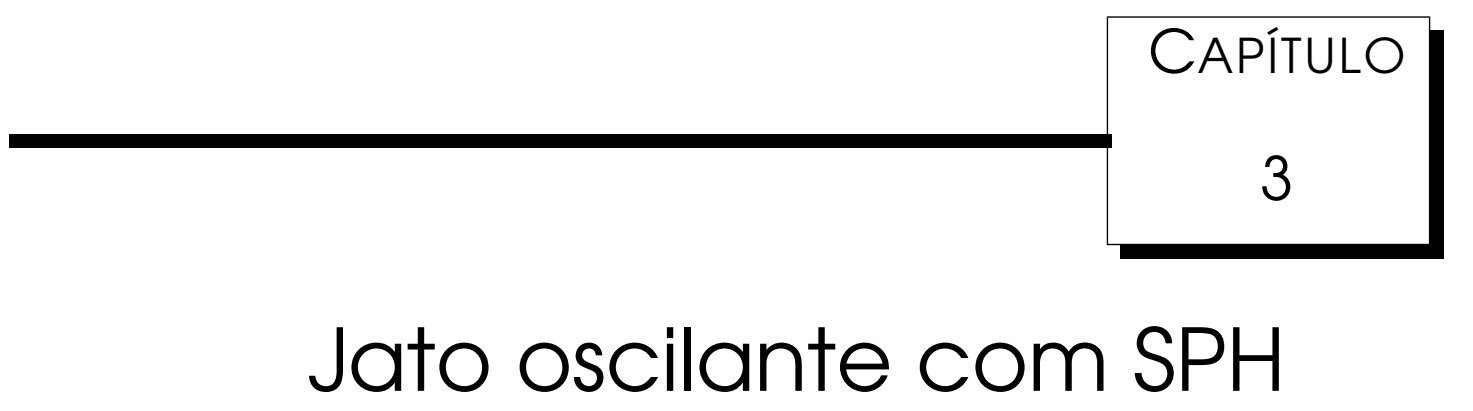

\footnotetext{
esta seção, o presente método SPH é estendido para simular o problema de jato oscilante, que envolve superfícies livres complexas e enrolamento das camadas do fluido. Este fenomeno tem sido estudado por alguns pesquisadores, mas sua teoria ainda não foi totalmente desenvolvida. Estimativas de oscilações em injetores Newtonianos foram feitos primeiramente por Cruickshank e Munson (1981) e Cruickshank (1988), essas estimativas são baseadas no comprimento do injetor $D$, a altura da entrada para uma placa rígida $H$ e o numero de Reynolds $R e$.
}

\subsection{Fluidos newtonianos e viscosidade}

Viscosidade é a medida da fricção interna de um fluido. Quando uma força externa é aplicada sobre o fluido, a viscosidade é a resistência à deformação.

A maioria das pessoas entende intuitivamente viscosidade para ser quão "grosso" é um fluido. A água pura é então entendida como sendo "fina", e o xarope é visto como sendo "grosso". Assim, a água tem um baixa viscosidade, e xarope tem uma viscosidade elevada. Para a vida cotidiana esse entendimento é geralmente suficiente. Na verdade a maioria dos fluidos que as pessoas enxergam como fluidos (substâncias aquosas) podem ser considerados geralmente como fluidos newtonianos, porque eles são puramente newtoniano ou seu comportamento pode ser aproximado por um modelo newtoniano.

Um fluido cuja tensão de cisalhamento é diretamente proporcional a taxa 
de deformação é conhecido como fluido newtoniano generalizado. Alguns exemplos de fluidos newtonianos generalizados incluem óleos, xarope, ar e outros gases.

A viscosidade pode ser decomposta em duas componentes; a viscosidade de corte que descreve a reação do fluido quando aplicada a tensão de cisalhamento e viscosidade de massa que descreve a reação a compressão.

\subsection{Fluidos não-newtonianos}

Um fluido não-newtoniano é um fluido cuja tensão de cisalhamento tem uma dependência não-linear em relação a taxa de deformação. Como consequência, fluidos não-newtonianos podem não ter uma viscosidade bem definida, pelo fato de serem não-linearmente dependentes a tensão de cisalhamento, assim como fatores externos, tais como tempo e temperatura. Quantificar e medir a viscosidade desses fluidos pode ser difícil pela dificuldade de isolar todos os fatores.

Fluidos não-newtonianos podem ser classificados pelos fatores que determinam seu comportamento, bem como os fatores externos sobre ele.

\subsubsection{Viscosidade dependente da tensão de cisalhamento}

Fluidos que são dependentes da tensão de cisalhamento são categorizados como dilatantes (viscosidade aumenta com o aumento da tensão) ou pseudoplástico (viscosidade diminui com o aumento da tensão).

Fluidos dilatantes são altamente contra-intuitivo no fato de sua viscosidade efetiva aumentar com o aumento da tensão aplicada. Este fenômeno é um bom tópico devido a potenciais aplicações para a tecnologia de vestuário de proteção, uma vez que permitiria o usuário mover-se com menos restrições do que uma armadura rígida, enquanto continuam a ser proteger contra impactos de alta velocidade. O efeito pode ser facilmente observado em uma mistura de amido de milho e água, e tem de fato sido popularizado com o grau em que programas de TV têm demonstrado o efeito enchendo piscinas inteiras com fluidos dilatantes, em seguida, demonstrando o efeito atravessando correndo sem afundar, e depois afundando quando em repouso.

Fluidos pseudoplásticos podem ser encontrados numa grande variedade de materiais, tais como lava, pintura, sangue e ketchup. 


\subsection{Modelo de Cross}

O modelo de Cross é um modelo reológico que pode ser usado para aproximar o comportamento real de um fluido não-newtoniano. Como visto em $\mathrm{Xu}$ et al. (2013b), neste modelo o tensor extra-tensão $\tau$ é descrito matematicamente por:

$$
\tau=2 \mu(|\mathbf{D}|) \mathbf{D} \quad \text { com } \quad \mu(|\mathbf{D}|)=\rho \nu(|\mathbf{D}|),
$$

onde $\mu$ é a viscosidade dinâmica, $\nu$ é a viscosidade cinemática e $\mathbf{D}$ é o tensor taxa de deformação dado por

$$
\mathbf{D}=\frac{1}{2}\left[\nabla \mathbf{v}+(\nabla \mathbf{v})^{\top}\right] .
$$

O termo $|\mathbf{D}|$ é a medida da magnitude da taxa de deformação:

$$
|\mathbf{D}|=\sqrt{2 \operatorname{tr}(\mathbf{D})},
$$

o simbolo tr denota o traço do tensor.

A viscosidade cinemática $\nu(|\mathbf{D}|)$ representa a natureza de afinamento do fluido e é uma função definida como

$$
\nu(|\mathbf{D}|)=\nu_{\infty}+\frac{\nu_{0}-\nu_{\infty}}{1+(K|\mathbf{D}|)^{m}},
$$

onde $K$ é o índice de fluxo de consistência, $m$ é o índice de fluxo, $\nu_{0}$ é o limite inferior da viscosidade e $\nu_{\infty}$ o limite superior. Este modelo pode ser usado tanto para fluidos pseudoplásticos $(m<1)$ quanto dilatantes $(m>1)$. Quando $m=1$ o modelo se reduz a um fluido newtoniano. Enquanto que os limites de viscosidade, $\nu_{0}$ e $\nu_{\infty}$, asseguram que o fluido se comporte como um fluido newtoniano em baixas taxas de cisalhamento e como um fluido não-newtoniano em altas taxas de cisalhamento.

\subsection{Discretização SPH do modelo de Cross}

Neste estudo é considerado tanto os fluidos newtonianos como os nãonewtonianos, desta maneira utilizamos o modelo de Cross como modelo reológico. Para fluidos não-newtonianos o cálculo da viscosidade é parte mais delicada, isto é, para cada partícula $i$ precisamos calcular $\tau_{i}$ dado por (3.1).

A aproximação SPH do tensor $\tau_{i}$ se reduz simplesmente a aproximação SPH 
do jacobiano da velocidade $\nabla \mathbf{v}_{i}$ que pode ser calculado por Paiva et al. (2009a):

$$
\nabla \mathbf{v}_{i}=\sum_{j \in N_{i}} \frac{m_{j}}{\rho_{j}}\left(\mathbf{v}_{j}-\mathbf{v}_{i}\right) \otimes \nabla W\left(\left\|\mathbf{x}_{i j}\right\|, h\right)
$$

onde $\otimes$ é o produto externo.

Finalmente, após atualizar $\tau_{i}$ para todas as partículas usando (3.1), a aproximação SPH das forças viscosas é dada de acordo com Paiva et al. (2009a) por:

$$
f_{i}^{\text {viscosidade }}=\frac{1}{\rho_{i}} \nabla \cdot \tau_{i}=\frac{1}{\rho_{i}} \sum_{j \in N_{i}} \frac{m_{j}}{\rho_{j}}\left(\tau_{i}+\tau_{j}\right) \cdot \nabla W\left(\left\|\mathbf{x}_{i j}\right\|, h\right) .
$$

\subsection{Jato oscilante}

Os primeiros estudos sobre jato oscilante feito por Cruickshank e Munson (1981) e Cruickshank (1988) mostraram que com as condições de $R e<0.56$ e $H / D>3 \pi$ o injetor formara a oscilação. Recentemente Bonito et al. (2006) apontou que o injetor newtoniano irá formar a oscilação quando ambas condições de $R e<0.53$ e $H / D=20$ forem satisfeitas, e suas descobertas são consistentes com a seguinte condição proposta por Tome e Mckee (1999):

$$
R e^{2} \leq \frac{1}{\pi} \frac{(H / D)^{2.6}-8.8^{2.6}}{(H / D)^{2.6}}
$$

Tais condições foram usadas para a simulação de jato oscilante neste trabalho. 


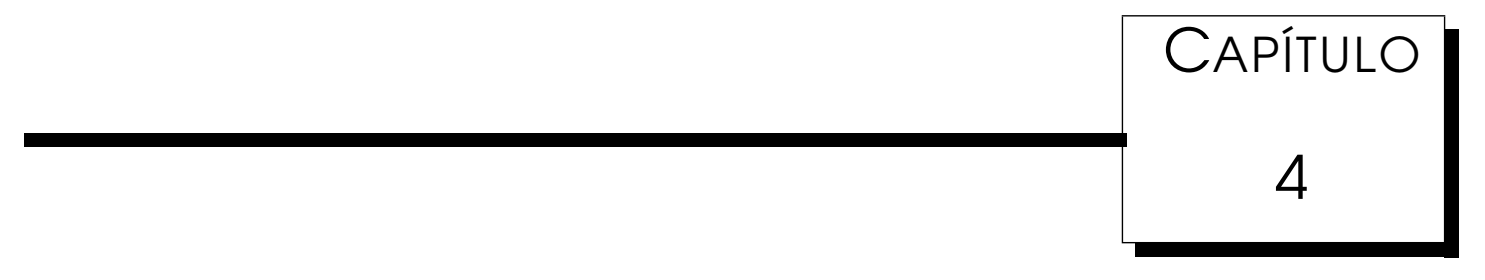

\section{Aspectos numéricos e computacionais}

e a física usa do cálculo infinitesimal para modelar a natureza, o computador infelizmente é limitado à operações algébricas com uma quantidade finita de números (Paiva et al., 2009b). Pensando nisso um caminho acessivel é aproximar matematicamente o modelo físico. Isto torna os aspectos computacionais um processo matemático delicado que deve respeitar o fenômeno físico. A escolha da aplicação corresponde a uma variação de estratégias de implementação, dependendo do contexto o código deve focar na eficiência, como em jogos, ou na precisão independente do custo computacional. Podemos observar que os tipos de simulação influenciam na escolha das estruturas de dados a serem usadas.

\subsection{Integração temporal}

Vimos que o método SPH nos permite calcular as derivadas a partir de amostras distribuídas aleatoriamente no espaço, obtendo assim as características necessárias para a simulação. Mas a equação de momento envolve derivadas espaciais e temporais do tipo:

$$
\frac{\partial \mathbf{v}}{\partial t}(t) \approx F(\ldots, \mathbf{v}(t-2 \Delta t), \mathbf{v}(t-\Delta t), \mathbf{v}(t), \mathbf{v}(t+\Delta t), \mathbf{v}(t+2 \Delta t, \ldots)
$$


Como podemos ver, a integração temporal se aparenta com a discretização de derivadas em grades, onde os métodos de diferenças finitas são os mais usados. Quando a função $F$ envolve apenas instantes de tempo anteriores a $t$ na incógnita a resolver, o método é chamado de explícito. Quando colocamos os instantes futuros em $F$ como incógnita e isolamos o instante atual, o método é chamado de implícito.

Independentemente da escolha do integrador temporal, para garantir a estabilidade numérica da simulação, o passo de tempo $\Delta t$ deve limitado pela condição CFL e também pelas condições das forças viscosas (Xu et al., 2013b):

$$
\Delta t \leq \min \left\{\frac{h}{c}, \frac{h^{2}}{8 \nu_{0}}\right\} .
$$

\subsubsection{Método de Euler}

O método de Euler é o mais simples que se tem conhecimento atualmente. Ele corresponde a uma aproximação da derivada temporal, que no caso da velocidade pode ser escrita como:

$$
\frac{\partial \mathbf{v}}{\partial t}(t)=\lim _{h \rightarrow 0} \frac{\mathbf{v}(t+h)-\mathbf{v}(t)}{h} \approx \frac{\mathbf{v}(t+\Delta t)-\mathbf{v}(t)}{\Delta t} .
$$

Este integrador é eficiente pois envolve apenas dois passos de tempo consecutivos: $t$ e $t+\Delta t$, no qual calcula o instante a seguir diretamente a partir do instante atual. Estimando a precisão a priori deste método aproximado por seu polinômio de Taylor, sua aproximação pode ser escrita como:

$$
\left(\frac{\partial \mathbf{v}}{\partial t}(t)\right)_{\text {Euler }}=\frac{\partial \mathbf{v}}{\partial t}(t)+O(\Delta t) .
$$

Com essa análise o método de Euler é qualificado de método de primeira ordem. Isso nos permite uma comparação de integradores temporais, e a baixa ordem deste integrador pode tornar uma simulação instável. Essa instabilidade pode ser contornada atribuindo um $\Delta \mathrm{t}$ muito pequeno.

No método Euleriano explicito a posição e velocidade são atualizadas em paralelo,

$$
\begin{aligned}
& \mathbf{x}_{t+\Delta t}=\mathbf{x}_{t}+\Delta t \mathbf{v}_{t}, \\
& \mathbf{v}_{t+\Delta t}=\mathbf{v}_{t}+\Delta t \mathbf{a}_{t} .
\end{aligned}
$$

Se a atualização da posição levar em conta a atualização na velocidade simul- 
taneamente, este método se torna o método euleriano semi-implícito,

$$
\mathbf{x}_{t+\Delta t}=\mathbf{x}_{t}+\Delta t \mathbf{v}_{t+\Delta t},
$$

no qual é mais estável que o método de Euler usual (Kelager, 2006).

\subsubsection{Método leap-frog}

O método leap-frog é um integrador que possui uma simplicidade como o método de Euler, mas com uma precisão de segunda ordem. Ele é baseado na estimativa da derivada temporal usando diferenças centradas em instantes de tempos fracionários (Paiva et al., 2009b):

$$
\frac{\partial \mathbf{v}}{\partial t}(t) \approx \frac{\mathbf{v}\left(t+\frac{1}{2} \Delta t\right)-\mathbf{v}\left(t-\frac{1}{2} \Delta t\right)}{\Delta t} .
$$

O método leap-frog obteve este nome pelo fato que a velocidade "pula"na frente da posição, e vice-versa (Kelager (2006)), produzindo um cálculo intercalado de posição e velocidade como ilustrado na Figura 4.1. A estrutura de integração é semelhante ao método de Euler:

$$
\begin{aligned}
& \mathbf{v}_{t+\frac{1}{2} \Delta t}=\mathbf{v}_{t-\frac{1}{2} \Delta t}+\Delta t \mathbf{a}_{t} \\
& \mathbf{x}_{t+\Delta t}=\mathbf{x}_{t}+\Delta t \mathbf{v}_{t+\frac{1}{2} \Delta t},
\end{aligned}
$$

onde a velocidade inicial é dada usando um passo do método Euler.

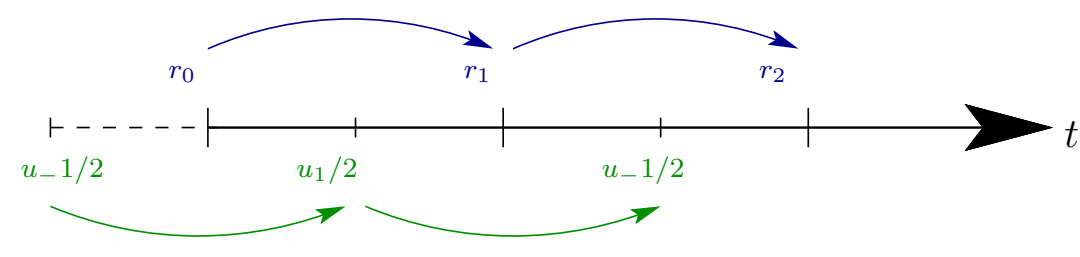

Figura 4.1: Representação dos saltos em leap-frog.

A velocidade no tempo $t$ pode ser estimada por uma simples aproximação média

$$
\mathbf{v}_{t} \approx \frac{\mathbf{v}_{t-\frac{1}{2} \Delta t}+\mathbf{v}_{t+\frac{1}{2} \Delta t}}{2},
$$

que é requerido quando computamos forças no tempo $t$. 


\subsection{Fronteiras}

A verificação de fronteira no método SPH é um aspecto muito importante pois define o comportamento de fluidos confinados ou em contato com outros corpos. Um fluido em contato com outro corpo pode se comportar de várias formas, dependendo das propriedades físicas do fluido e do corpo em contato, o fluido pode apresentar fenômenos como capilaridade, molhamento, tensão e fricção. Esses fenômenos são complexos e não são bem modelados pela física ainda, por isso os métodos de verificação de fronteira são aproximativos no que se trata destes fenômenos.

O uso de partículas fantasma para descrever uma fronteira significa usar de partículas virtuais, fora da fronteira, de forma que essas partículas formem uma força de repulsão que mantenha as partículas reais dentro do domínio, como visto em Paiva et al. (2009a). As características principais dessas partículas, como pressão, velocidade, densidade e posição podem ser definidas como a reflexão de partículas reais situadas próximas à fronteira, como visto na Figura 4.2, porém essa abordagem se torna complexa de se manter para fronteiras geometricamente mais complexas.

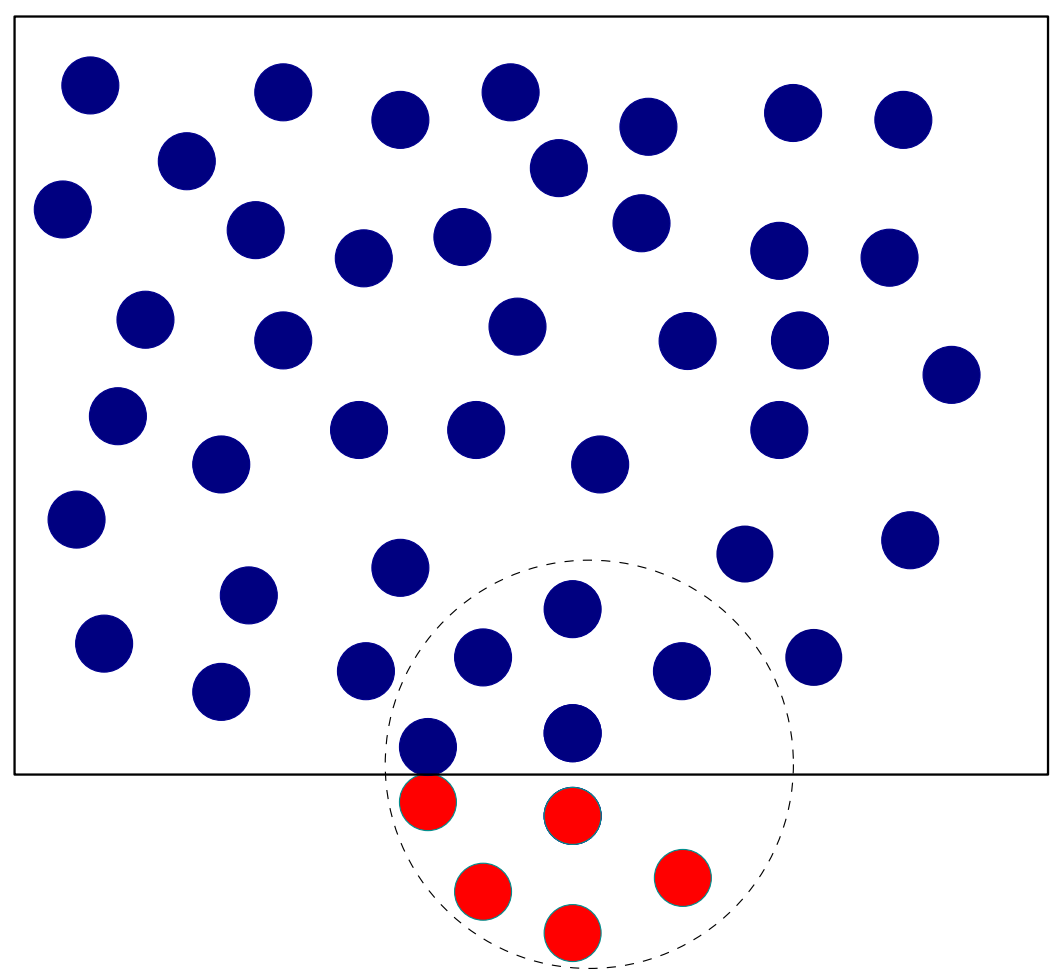

Figura 4.2: Fronteiras por partículas fantasmas dispersas

Outra abordagem seria distribuir as partículas virtuais uniformemente ao 
longo da fronteira, como visto na Figura 4.3, com isso a nossa fronteira pode ser mais facilmente mantida, porém nessa abordagem precisamos calcular as propriedades das partículas de modo a manter a fronteira.

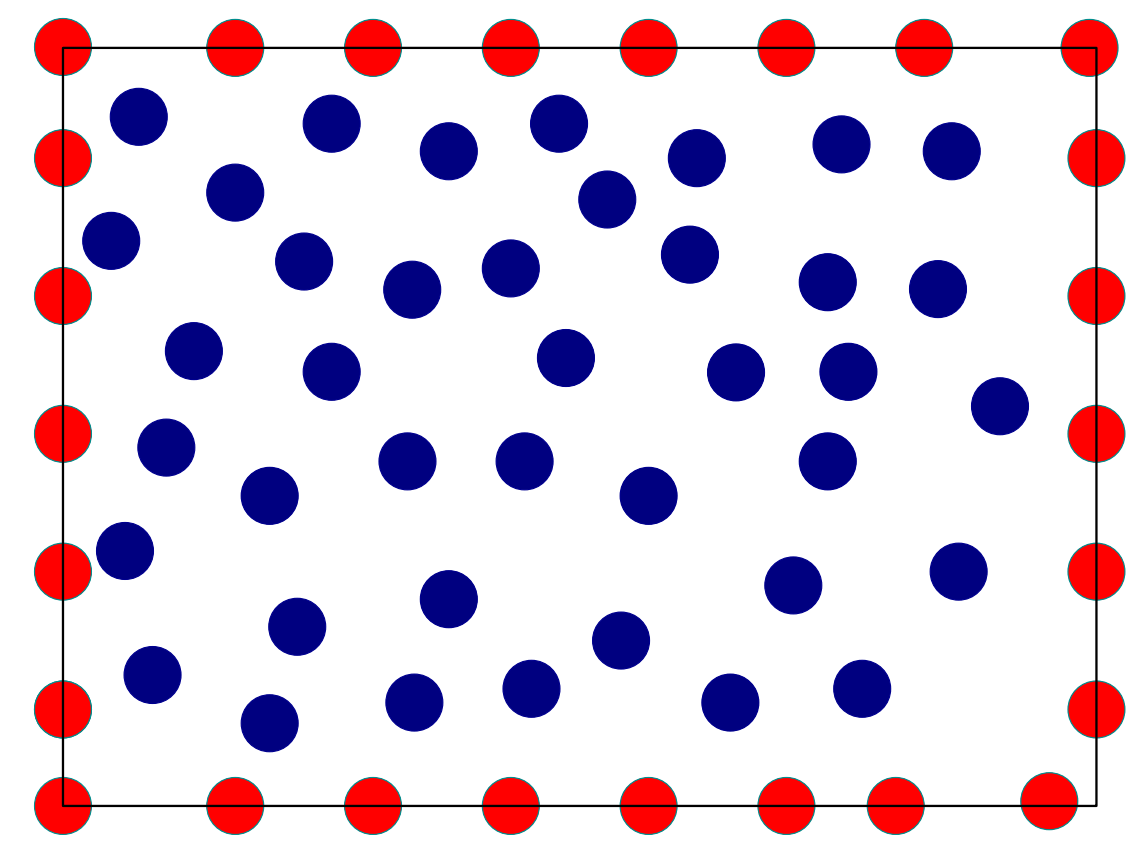

Figura 4.3: Fronteiras por partículas fantasmas uniformes

Definir formas a partir de malhas de triângulo é o método mais usado em computação, então descrever a fronteira dessa forma facilita até mesmo a integração com outros modelos geométricos ou sistemas de simulação já existentes.

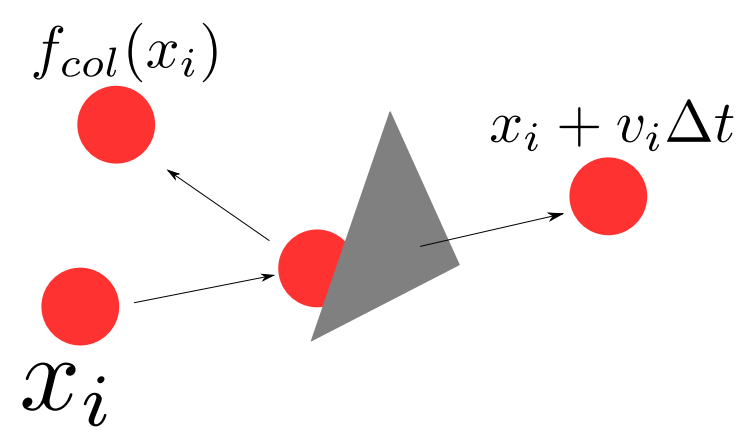

Figura 4.4: Colisão partícula $\mathrm{x}$ triângulo, a partícula com posição $x_{i}$ tem sua trajetória alterada de $x_{i}+v_{i} \Delta t$ para $f_{c o l}\left(x_{i}\right)$, onde $f_{c o l}$ é a função que trata a colisão entre a partícula e o triângulo.

Esse método de tratamento consiste em tratar a partícula como um corpo que se choca contra uma parede, calculando a sua trajetória após a colisão. No caso, ao atualizar a posição de uma partícula, verificamos se a sua trajetória 
intercepta algum triângulo e caso intercepte, calculamos a nova posição e velocidade da partícula. Esse cálculo pode ser feito de diversas formas, como por exemplo usar a lei de Snell-Descartes, invertendo o vetor velocidade em relação à normal do triângulo como na Figura 4.4. Podemos também adicionar coeficientes de fricção e restituição para simular efeitos de escorregamento e elasticidade, respectivamente. Uma colisão elástica e/ou escorregadia usa os coeficientes de fricção e restituição para amortecer as componentes tangencial e normal do vetor velocidade da partícula com relação à normal do triângulo.

\subsection{Particulas vizinhas}

No SPH todas as operações sobre uma partícula dependem das propriedades das suas partículas vizinhas. Num sistema onde a cada passo de tempo as partículas se rearranjam no espaço, modificando o que podemos chamar de conjunto de vizinhos de uma partícula, manter esse conjunto é um trabalho que deve ser feito continuamente e requer um grande esforço. Realizar a detecção de vizinhos de forma eficiente contribui consideravelmente para o desempenho do sistema.

O algoritmo mais simples é considerar cada par de partículas, e verificar a distância entre elas, no qual podemos chamar de algoritmo força bruta. Se esta distância for inferior a $\kappa h$ (raio de influência do núcleo SPH) elas são vizinhas. Este algoritmo necessita de muito esforço computacional e pouco trabalho de raciocínio. Devemos entender o porque ele pode ser desastroso e como podemos torná-lo bom com certas configurações.

Considerando que o sistema tem $n$ partículas, e em média $k$ vizinhos. Onde $n$ seja na ordem de milhares a centenas de milhares, e $k$ apenas de algumas dezenas. O tempo de busca será o número de pares distintos ordenados de partículas vezes o tempo de achar os pares e efetuar os testes para ver se são duas partículas vizinhas, e ainda o tempo de retornar as $k n$ vizinhas. Se $n$ for muito grande, o tempo cresce como $O\left(n^{2}\right)$, pode significar muito tempo de computação.

Podemos melhorar este método fazendo algumas observações. Em caso de partículas que se movem pouco, seus vizinhos raramente mudam. Assim calculamos seus vizinhos apenas quando eles mudam; este processo é chamado de atualização preguiçosa. Podemos testar se uma partícula vai mudar de vizinho observando se ela percorreu mais de $1 / 2 h$. Isto ocorre em um tempo médio $t$, onde esse tempo é baseado na velocidade media de uma partícula. Se 
$t$ for comparável com $n$, a busca força bruta com atualização preguiçosa pode ser eficiente.

Uma outra maneira de tentar melhorar o método, é se utilizando do fato que se uma partícula $x$ é vizinha de $y$, então pode-se registrar que $y$ é vizinha de $x$, dessa forma o tempo de computação pode ser reduzido.

Apesar da sua simplicidade o algoritmo força bruta apresenta um desempenho muito ruim quando falamos de uma aplicação interativa. Para melhorar o tempo de detecção de vizinhança e o desempenho da aplicação num todo, uma técnica comum é a divisão do espaço em células. O espaço dividido em células do mesmo tamanho, de forma regular, é chamado de grade regular ou simplesmente grade.

A maior vantagem de uma grade regular é descartar partículas que estão a uma distância maior que o raio de influência de uma partícula, dessa forma descartamos uma grande parcela de cálculos de distância desnecessários. Ao dividir o domínio da simulação em células com lado igual a $\kappa h$, os vizinhos de uma partícula estarão localizados na mesma célula que ela ou nas células adjacentes fazendo com que a busca de vizinhos fique restrita a $3^{d}$ células vizinhas onde $d$ é a dimensão do espaço de simulação (2D ou 3D).

A Figura 4.5 mostra num espaço bi-dimensional uma partícula $i$ e as células onde será realizada a busca dos seus vizinhos. Essa técnica é eficiente quando o domínio da simulação é compacto e a densidade de partículas é grande, pois o número de partículas por célula da grade tende a ficar distribuído de forma homogênea.

Apesar de ser eficiente, o sistema de grade regular pode ser melhorado com algumas modificações. Uma delas é a utilização de uma grade regular virtual para economizar memória e reduzir o número de células vazias. Utilizando uma grade virtual de dimensões $w \times h$ células, cada célula com lado igual a $\kappa h$ e tendo uma partícula $p$ com posições definidas por $p x$ e $p y$, as operações $i=p x / \kappa h$ e $j=p y / \kappa h$ nos dão os índices $i$ e $j$ da célula onde a partícula seria armazenada em uma grade comum. Com os índices $i$ e $j$, as operações $i^{\prime}=i \bmod w$ e $j^{\prime}=j \bmod h \operatorname{nos}$ fornecem os índices $i^{\prime}$ e $j^{\prime}$ de onde a partícula $p$ será armazenada na nossa grade virtual.

Com o uso de uma grade virtual as células vizinhas poderão conter partículas que não são vizinhos reais da partícula em questão, mas isso ainda é um problema que pode ser facilmente contornado sem maiores complicações ou perda de desempenho. Outro ponto importante do uso de uma grade virtual é a possibilidade de organizarmos os dados das partículas na memória de 


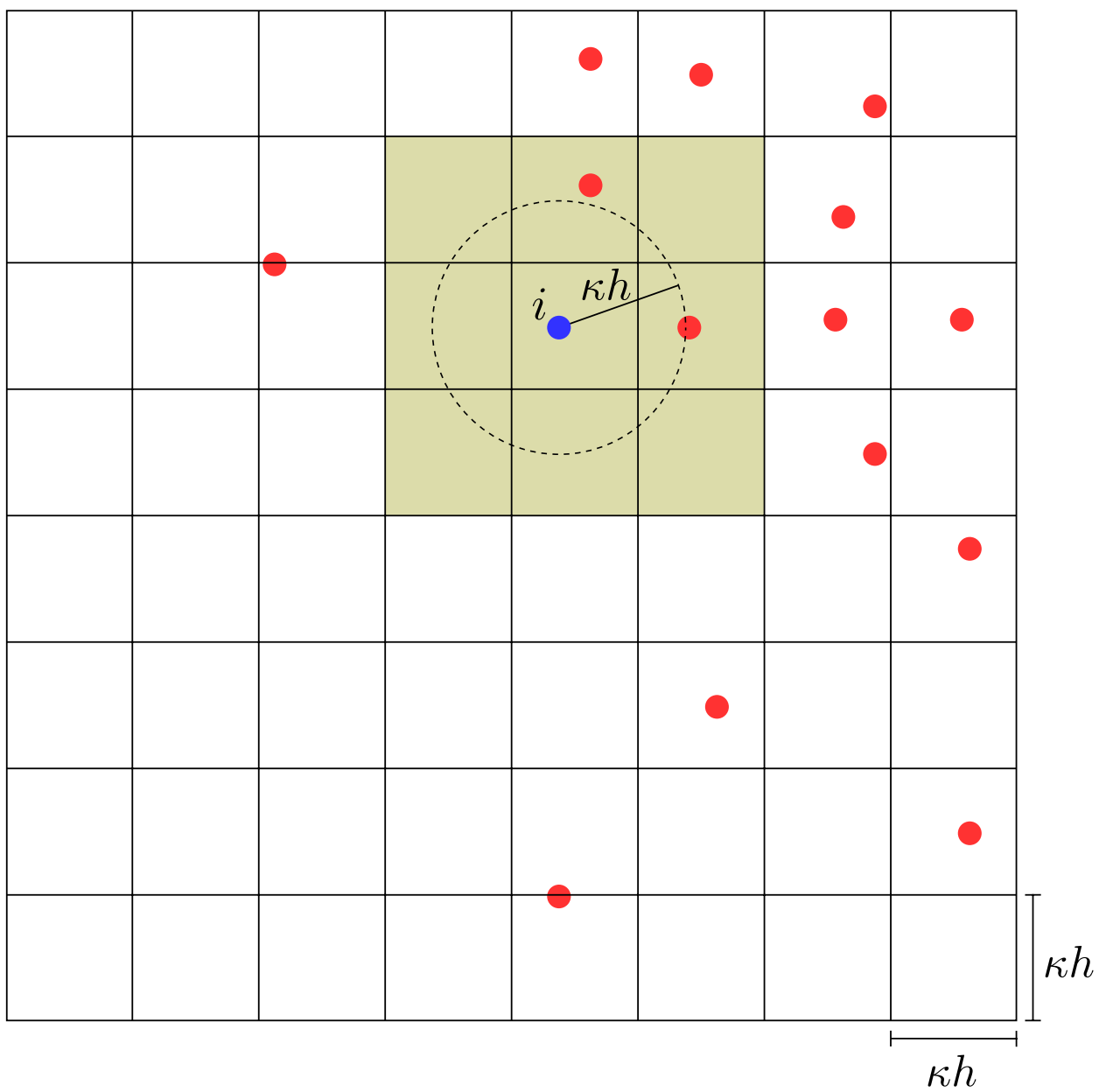

Figura 4.5: Grade regular num espaço bi-dimensional, as células destacadas representam as células que contêm os vizinhos da particula $i$.

forma que possamos tirar proveito da localidade espacial e temporal da cache de memória.

O ponto mais fraco no uso de grades regulares é que em aplicações onde as partículas são mais dispersas, muitas células ficam vazias enquanto outras podem ficar com muitas partículas. Outro ponto é o fato de grades regulares serem divididas em células com lado igual ao raio de suavização das partículas o que impede de utilizarmos partículas com diferentes raios de suavização.

Estruturas adaptativas que modificam-se constantemente para se adequar a posição das partículas e a sua estrutura mais comum é a partição binária do espaço. Inicialmente na partição binária do espaço, o espaço é uma única célula que engloba todas as partículas e então esse espaço é subdividido recursivamente até que cada subdivisão contenha o número máximo de partículas por célula da estrutura. Por ser uma estrutura hierárquica, a melhor maneira de armazenarmos a estrutura na memória é como uma árvore, 


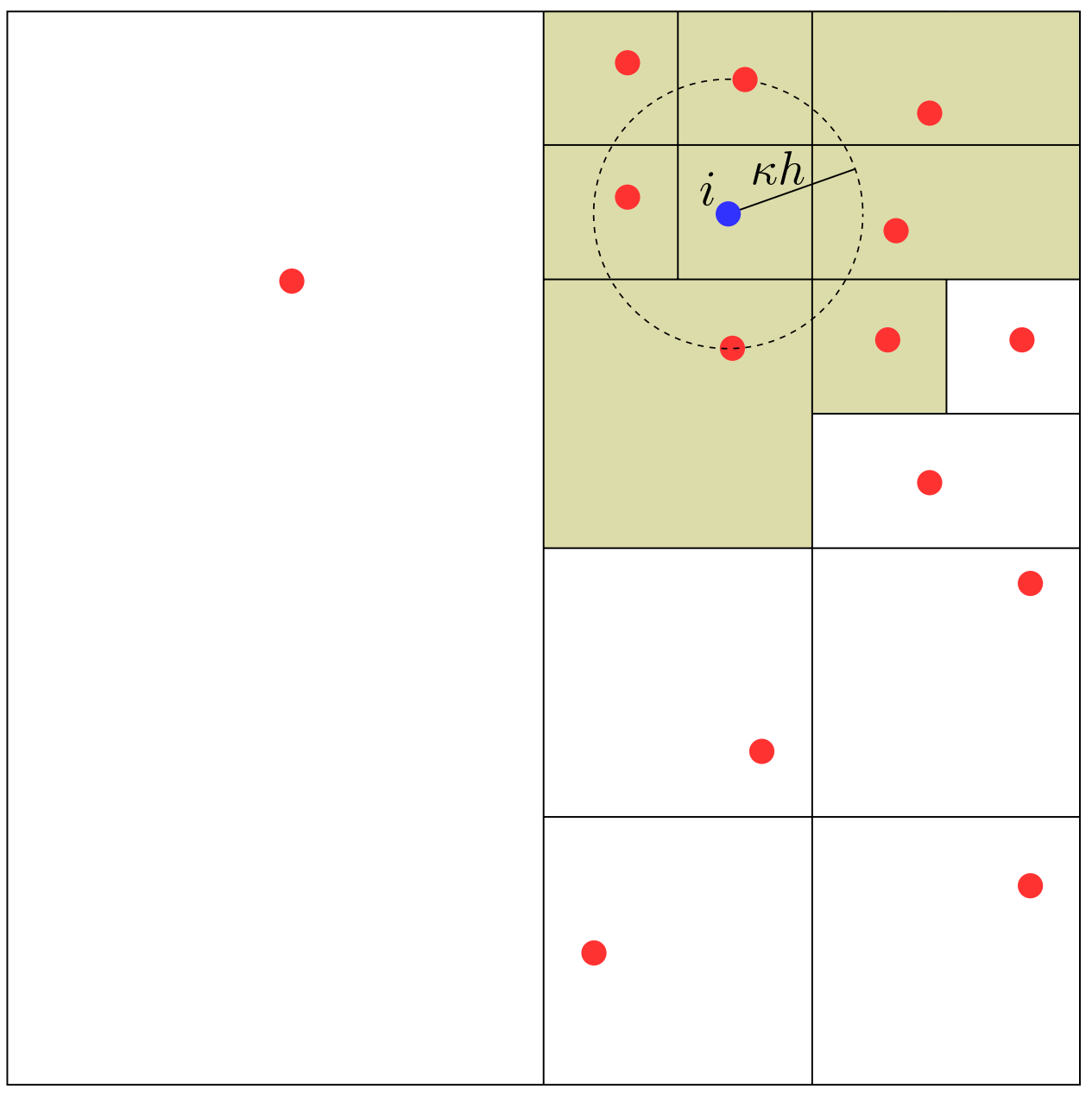

Figura 4.6: Quadtree num espaço bi-dimensional, as células subdividem-se de forma hierárquica para se adaptarem à localização das partículas.

geralmente uma $k d$-tree, ou uma octree para espaços tridimensionais ou quadtree para espaços bidimensionais como visto na Figura 4.6. A desvantagem em usar estruturas adaptativas é que em casos onde a dispersão de partículas é muito grande o consumo de memória pode ficar maior que uma grade regular além de o percurso em árvore ser mais dispendioso que o acesso direto às células da grade regular.

Analisando as vantagens e desvantagens acima apresentadas, neste trabalho é utlizado o esquema de grades virtuais na implementação.

As aplicações do método SPH precisam integrar áreas de matemática e computação que são significativas por si mesmas, em particular: equações diferenciais numéricas, mecânica dos fluidos computacional, estrutura de dados, processamento geométrico e rendering. 


\subsection{CUDA}

Atualmente a potencialidade da Computação Gráfica está intimamente relacionada com a evolução dos computadores, em termos de hardware e software. Com o avanço da tecnologia a cada ano novos e melhores hardwares são lançados o que permitiu a utilização de GPU para resolver problemas não relacionados à Computação Gráfica, isso teve início já na segunda geração de GPU(1999-2000). Da sua segunda geração até hoje, as GPU foram adaptadas para facilitar a sua programação e tal facilidade fez com que elas fossem aplicadas na solução de problemas genéricos, surgindo a ideia de GPGPU.

As GPU foram criadas para processar pixels e vértices de forma paralela, ao trazer essa paralelização para o desenvolvimento de aplicações genéricas, a GPU passa a ser vista como uma unidade de processamento paralelo de baixo custo. Tendo isso em vista, a sua arquitetura passou a ser adaptada para facilitar tal uso, além de serem fornecidas API próprias para programação em GPU pelas fabricantes de hardware, como a NVIDIA que fornece ferramentas para uso com a CUDA e a ATI que por algum tempo manteve o CTM e hoje desenvolve o StreamSDK.

Antes de desenvolver uma aplicação em GPU deve-se analisar o problema, definir se existe uma solução que pode tirar proveito do paralelismo da arquitetura e escrever um algoritmo paralelo para isso. Alguns fatores importantes para avaliar se um problema terá algum ganho quando resolvido em CUDA são:

- A existência de um algoritmo paralelo eficiente;

- Intensidade numérica do problema;

- Coalescência de memória.

Dado que existe um algoritmo paralelo eficiente para resolver o problema, a intensidade aritmética se refere ao trabalho que será executado pelas thread em paralelo, muitos cálculos com pouco acesso à memória representam um problema de grande intensidade aritmética. A coalescência de memória é importante para aproveitar o modelo de memória da CUDA que permite a leitura de mais de um elemento de memória ao mesmo tempo, mas isso possui algumas regras que devem ser respeitadas. Tais regras podem ser resumidas a: a thread $i$ deve acessar o vetor de dados na posição de memória $i$ em relação ao endereço base, sem deslocamentos ou falhas entre a leitura, ou escrita dos 
dados pelas thread e de forma alinhada. O acesso alinhado à memória é feito quando são lidos blocos de 4,8 ou 16 bytes com endereços múltiplos de 4 , 8 ou 16, por isso nossas estruturas devem ter 4,8 ou 16 bytes e caso sejam maiores que isso, devemos dividi-las em estruturas menores. Essas regras garantem que thread rodando em paralelo acessem a memória de forma mais eficiente.

O driver controlador do dispositivo CUDA controla a execução de tarefas no dispositivo de forma a permitir a execução de mais de uma tarefa de forma escalonada, fazendo com que o mesmo dispositivo realize computação geral e controle a saída de vídeo do sistema.

O desenvolvimento de aplicações em CUDA conta com um conjunto de bibliotecas fornecidas pela NVIDIA que trabalham como intermediárias entre a aplicação e o dispositivo. Não é possível que a aplicação comunique-se diretamente com o hardware, tal comunicação deve ser feita através do driver da CUDA, de bibliotecas de tempo de execução (runtime) ou de bibliotecas de alto nível, todas fornecidas pela NVIDIA. Tal organização de dispositivos e bibliotecas pode ser visto na Figura 4.7.

A CUDA possui um modelo de memória em vários níveis como visto na Figura 4.8. Esse modelo de memória permite que sejam feitas algumas otimizações no acesso à memória como utilizar a memória constante ou de textura para dados que apenas serão lidos. A vantagem da memória de textura é a cache de dados mais eficiente que a memória global que carrega dados adjacentes para a cache, seja em arranjos de dados 1D, 2D ou 3D. Por exemplo: no caso de arranjos 2D como matrizes a cache é feita com os dados adjacentes em todas as direções da posição acessada. A memória constante pode ser escrita apenas a partir do código executado em CPU, possui uma velocidade de leitura maior que as demais e seu tamanho é muito reduzido (na ordem de $64 \mathrm{~KB}$ apenas) por isso ela é mais adequada para armazenar, por exemplo, parâmetros de execução.

Usando CUDA, a GPU passa a ser vista como um co-processador da CPU permitindo que tarefas sejam atribuídas à GPU enquanto a CPU continua a execução normal da aplicação. Apesar das vantagens apresentadas, algumas limitações ainda são encontradas na arquitetura: funções recursivas não são suportadas, orientação a objetos é parcialmente suportada e apenas em dispositivos mais novos e a largura de banda do barramento de dados e a latência entre CPU e GPU podem provocar gargalo na transferência de dados. 


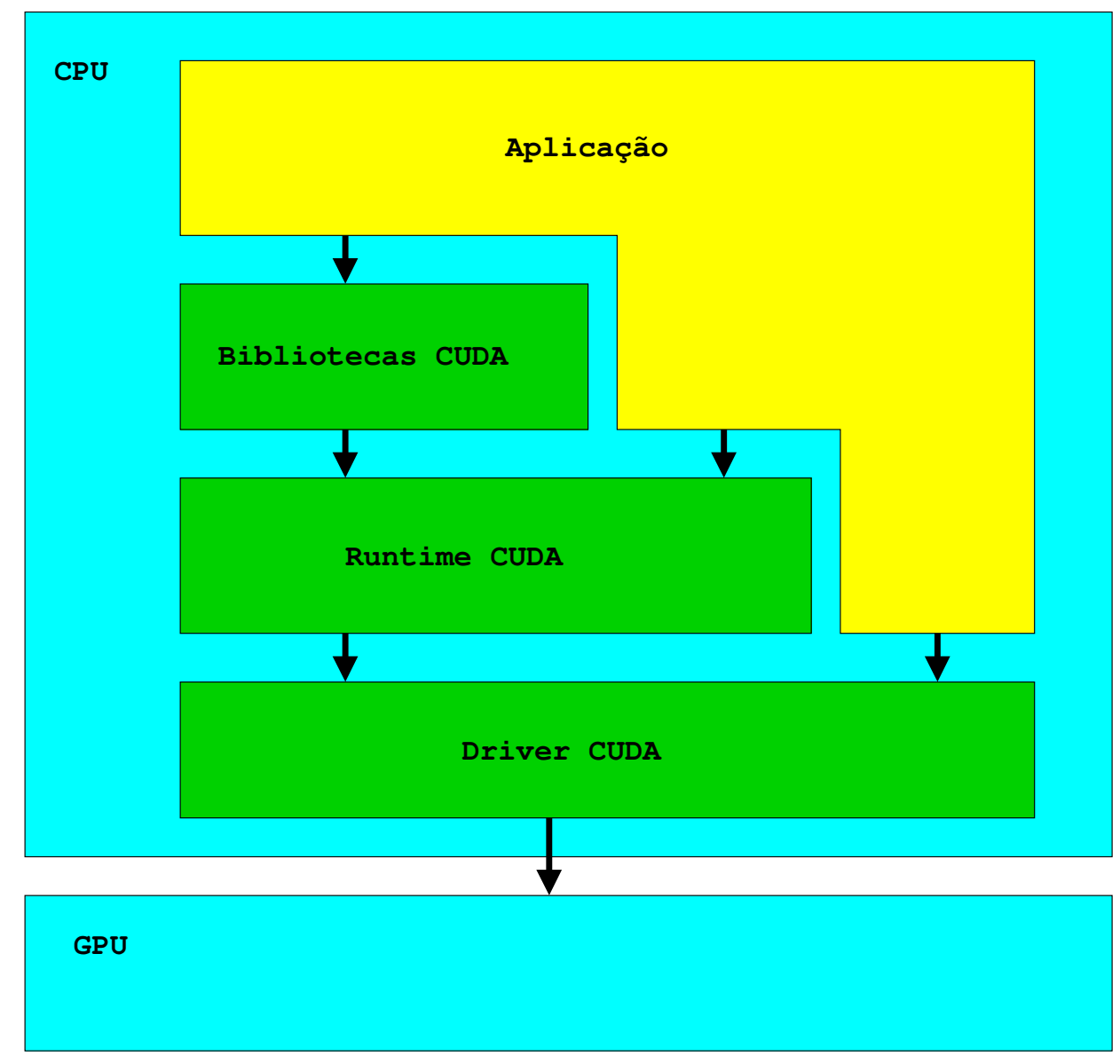

Figura 4.7: Pilha de aplicação CUDA.

\subsubsection{CUDA e SPH}

Deve-se estudar os aspectos referentes a implementação do método SPH em CUDA: estruturas de dados e busca de vizinhos. A modelagem das estruturas de dados pode ser feita de diferentes formas usando vetores de estruturas ou estruturas de vetores, o mais importante na definição das estruturas é permitir o acesso coalescente à memoria. E junto com uma ordenação de dados eficaz modelar a busca de vizinhos.

\section{Estruturas de dados e memória}

A estrutura de dados foi modelada como uma estrutura de vetores: vetores para velocidade, posição, densidade, pressão, aceleração e vetores auxiliares para a parte de ordenação de dados. As grandezas escalares como pressão e densidade podem ser armazenadas em um vetor de números reais com precisão simples que na linguagem $\mathrm{C}$ ocupam 4 bytes cada, dessa forma o acesso à memoria é feito de forma alinhada. As grandezas vetoriais como velocidade e 


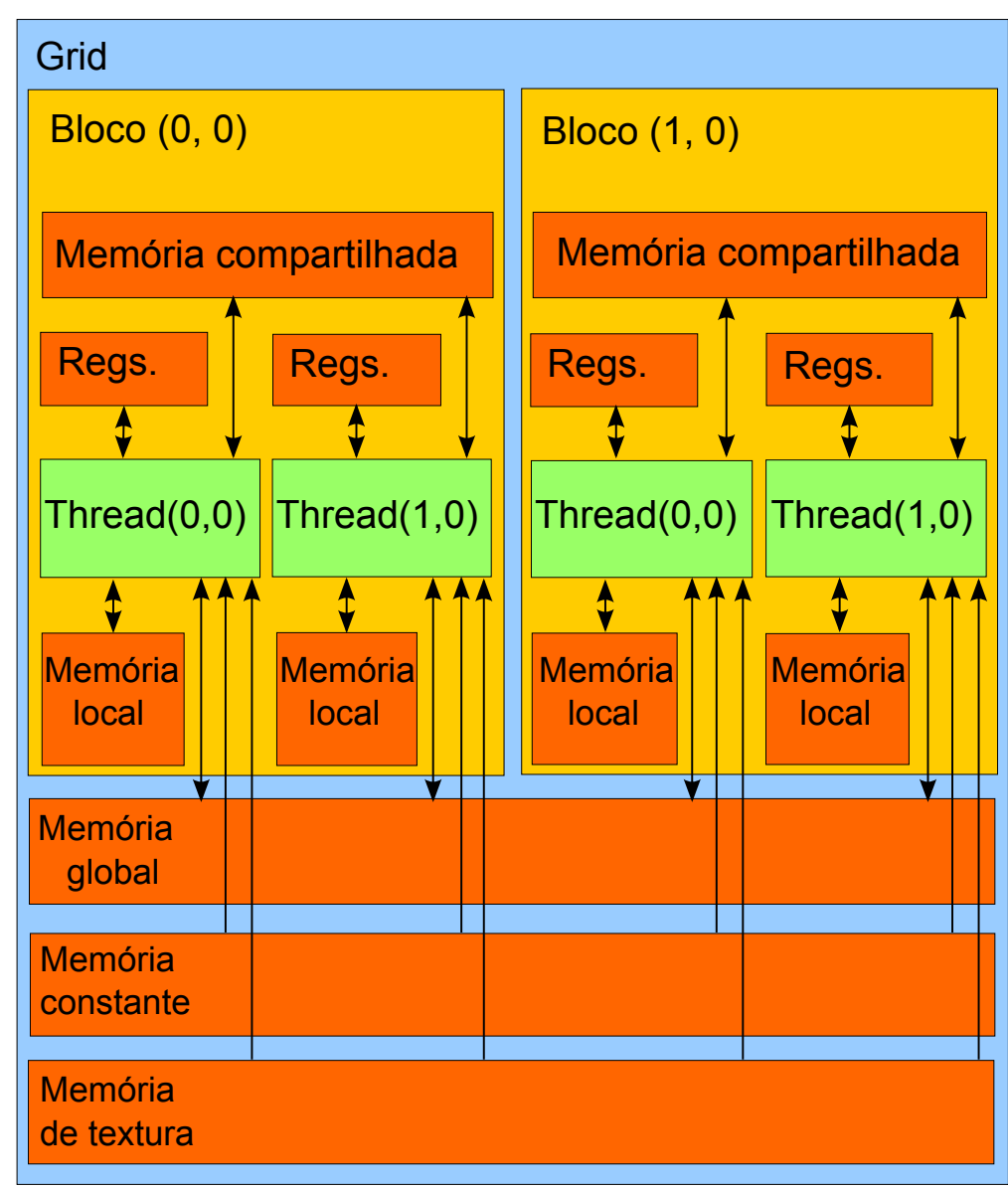

Figura 4.8: Modelo de memória da CUDA, as setas indicam a direção de acesso à memória. No caso das memórias constante e de textura, é permitido apenas a leitura.

aceleração devem ser armazenadas em vetores de estruturas capazes de comportar as componentes $x, y$ e $z$ do vetor. Uma estrutura com três números reais com precisão simples em $\mathrm{C}$ ocupa 12 bytes o que faz com que em CUDA sejam necessárias três transações de leitura. Ao usarmos uma estrutura com um componente adicional, $w$, que não será considerada nos cálculos, a nossa estrutura de armazenamento passa a ocupar 16 bytes de memória como visto na figura 4.9, permitindo que a sua leitura seja feita com apenas uma transação. Por esse motivo, todas as nossas grandezas vetoriais foram armazenadas em estruturas com quatro componentes.

A grade usada para detecção de vizinhança é representada na memória de forma linear onde as $w \times h \times d$ células são tratadas como um arranjo unidimensional, através de um vetor que contem os índices originais das partículas na memória, um que guarda a sua posição na grade e dois auxiliares que indicam a posição de início e fim de cada célula no vetor. Dessa forma inde- 


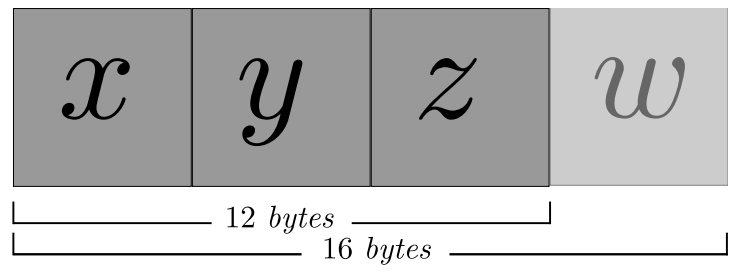

Figura 4.9: Estrutura de armazenamento não alinhada e estrutura alinhada a 16 bytes.

pendentemente da distribuição das partículas nas células, células vazias ou excessivamente cheias não causam problemas de memória.

\section{Ordenação de dados}

Uma importante tarefa para manter a eficiência do método SPH é encontrar os vizinhos de uma partícula de forma eficiente, temos então que manipular nossas estruturas de dados de forma a facilitar essa busca e uma boa maneira de fazer isso é ordenando nossos vetores de partículas em relação às células da grade regular e em relação às próprias partículas, assim temos que a busca por vizinhos para cada partícula é feita apenas na célula que contém a partícula e nas 26 células adjacentes.

Ao escolher um algoritmo para a ordenação em CUDA devemos levar em conta mais do que complexidade assintótica do algoritmo, pois um algoritmo considerado eficiente quando executado em CPU pode não ser tão bom quando implementado em GPU. Uma das bibliotecas fornecidas com o SDK da CUDA é a CUDPP que dentre outros primitivos paralelos, fornece uma implementação eficiente do radix sort. A implementação de tais primitivos é discutida em Harris et al. (2007) e Sengupta et al. (2007), que mostram também a eficiência da implementação fornecida pela biblioteca. Por esses motivos nesta implementação é utilizada esta biblioteca através da interface de alto nivél Thrust (Hoberock e Bell, 2010).

Usando a implementação do radix sort fornecida pela Thrust, a ordenação dos dados é feita com base na célula da grade em que a partícula se encontra, isso divide os dados na memoria como se as células estivessem em sequência num arranjo 1D como visto na figura 4.10 .

\section{Vizinhança}

A nossa busca de partículas vizinhas usa uma grade regular virtual. As dimensões da nossa grade são de $64 \times 64 \times 64$ células, então dada uma partícula 


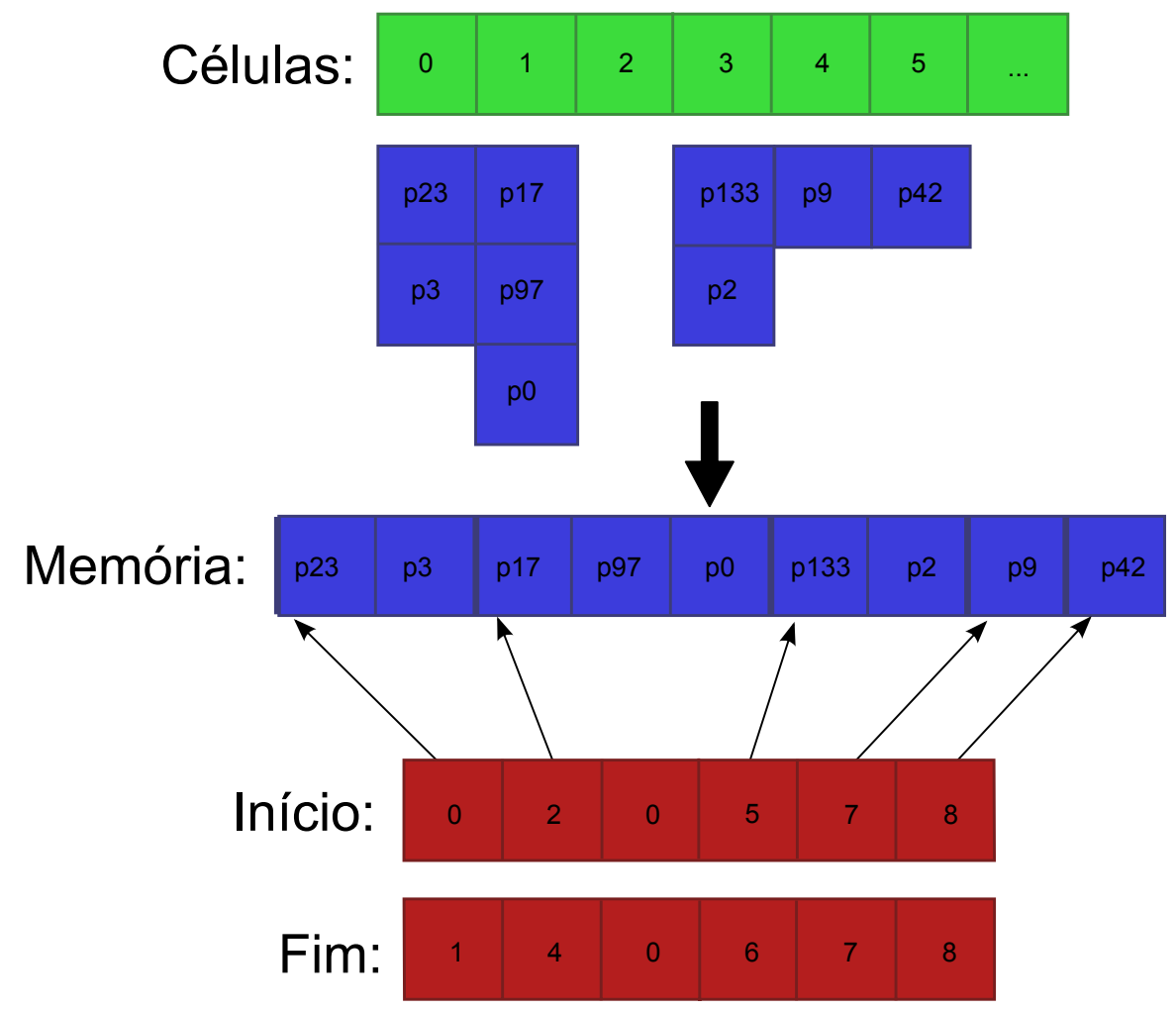

Figura 4.10: Ordenação das partículas de acordo com a sua posição na grade.

com posição $p$ e sendo a origem do sistema no ponto $o$, a sua localização $(i, j, k)$ na grade é dada por:

$$
\begin{aligned}
& i=\left(\left\lfloor\frac{p . x-o . x}{\kappa h}\right\rfloor\right) \quad \bmod 64, \\
& j=\left(\left\lfloor\frac{p . y-o . y}{\kappa h}\right\rfloor\right) \quad \bmod 64, \\
& k=\left(\left\lfloor\frac{p . z-o . z}{\kappa h}\right\rfloor\right) \quad \bmod 64 .
\end{aligned}
$$

As equações 4.12 fornecem os indices $(i, j, k)$ da célula na grade onde a partícula $p$ se encontra. Como as partículas vizinhas de $p$ encontram-se na mesma célula ou nas células adjacentes, o algoritmo 2 mostra como percorrer essas células e o 3 mostra como utilizar os dados de cada célula vizinha. A cada célula analisada, as partículas nela contidas podem ser vizinhas ou não de $p$, isso é um efeito normal causado pelo fato de várias células de uma grade real serem mapeadas para a mesma célula da grade virtual. Os cálculos das forças são feitos com todas as partículas da célula analisada incluindo as falsas vizinhas mas isso não causa problemas nos resultados pelo fato de os núcleos SPH possuírem suporte compacto, ou seja, o cálculo das forças entre $p$ 
e partículas que pertencem a uma célula vizinha mas na verdade estão a uma distância maior do que $\kappa h$ de $p$ resulta em zero. Apesar de falsos vizinhos não causarem problemas numéricos, realizar todo os cálculos de pressão, densidade e viscosidade para essas partículas gasta tempo e reduz o desempenho da aplicação, por isso deve-se ter o cuidado de descartar o mais cedo possível essas partículas para economizar tempo. Esse descarte de falsos vizinhos melhorou em torno de $30 \%$ o desempenho geral da aplicação.

1 Obtenha os índices $(i, j, k)$ da partícula na grade;

2 para $\Delta i \leftarrow-1$ até 1 faça

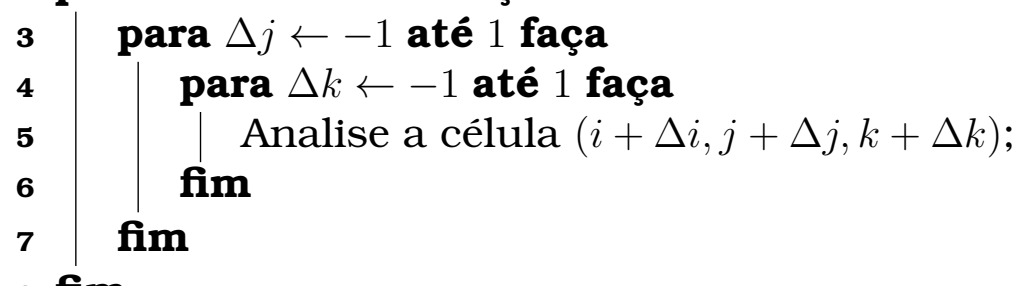

8 fim

Algoritmo 2: Algoritmo de utilização da grade regular virtual.

1 Obtenha a posição $p_{i}$ da partícula $i$;

2 Obtenha os índices de início e fim da célula na grade;

3 se a célula não está vazia então

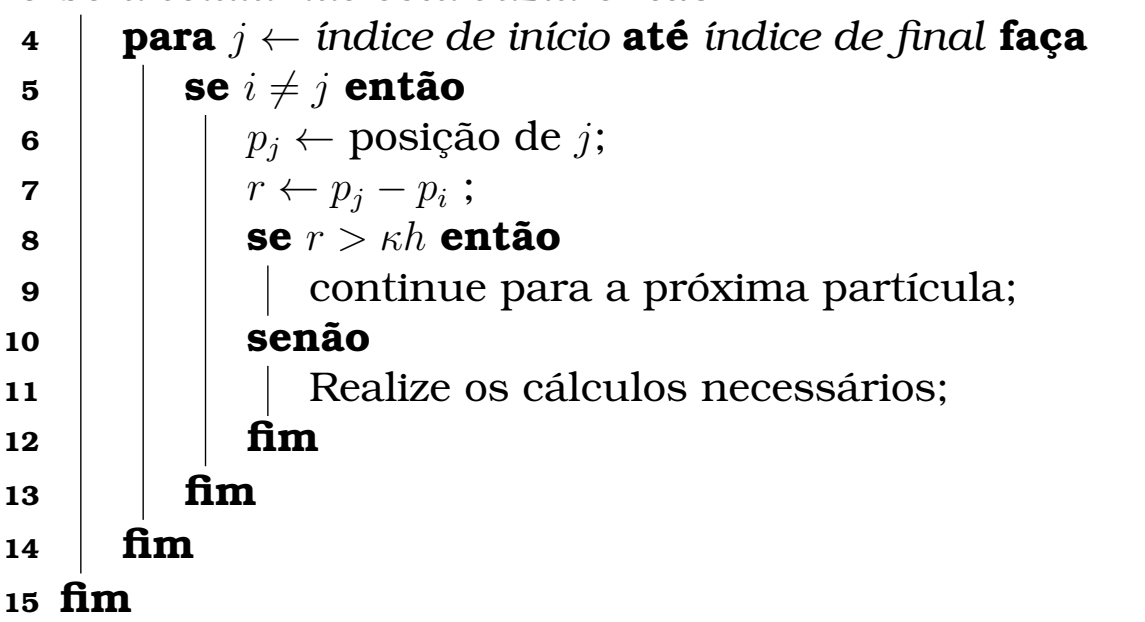

Algoritmo 3: Algoritmo de atravessamento de uma célula da grade.

\subsection{Implementação SPH em CUDA}

Como visto em Herault et al. (2010), o método SPH é computacionalmente intensivo, ou seja, possui uma grade intensidade aritmética pois toda atualização em uma partícula envolve cálculos de densidade, viscosidade, pressão, distância entre as partículas, funções de suavização, etc. Não há dependência 
de informação entre as partículas durante um somatório SPH, pois os dados das vizinhas a serem usados nos cálculos são todos passo anterior, por isso não existe troca de dados entre threads durante o processamento, isso facilita muito o trabalho com CUDA pois a comunicação entre threads precisaria ser feita através da memória global. Essas características facilitam a escrita do algoritmo paralelo.

Temos investigada as possibilidades de criar de forma interativa uma simulação de jato oscilante, e descobrimos que simulação de fluidos em SPH com suporte para viscosidades não-newtonianas é a melhor escolha para isto. SPH é bem adequado para uma implementação baseada em GPU, e temos demonstrado em Krog e Elster (2012) que SPH em GPU rende um bom desempenho.

Para alcançar um alto desempenho fazemos uso de uma estrutura de dados de aceleração, que faz com que seja possivel explorar o poder da GPU. E ainda otimizações no código em si.

A implementação deste trabalho contém dois modelos SPH:

- Modelo SPH simples: modelo é baseado em Müller et al. (2003) com objetivo de animar fluidos em taxas interativas.

- Modelo SPH viscoso: modelo um pouco mais sofisticado que combina o método proposto por Müller et al. (2003) com modelo reológico de Cross (Xu et al. (2013a)).

\subsection{Algoritmo SPH paralelo}

Ambos os modelos SPH usam os mesmos passos básicos nos algoritmos. Uma iteração do algoritmo é um passo de tempo, de modo que todos os passos do algoritmo deve ser executado de cada vez.

O primeiro passo é atualizar a estrutura de dados para aceleração.

No segundo passo o cálculo da aproximação SPH das forças resultantes deve ser feito. A ordem em que essas forças são calculadas é impulsionada por dependências de dados entre os cálculos. Em SPH, o cálculo da força dependente da densidade, logo a aproximação SPH da densidade deve ter prioridade em relação a aproximação dos demais atributos físicos de cada partícula.

Por último, a integração temporal da aceleração através da aproximação SPH das forças resultantes.

Como podemos observar o algoritmo 4 não sofre muitas alterações em relação ao algoritmo 1. A idéia é atribuir uma thread para cada partícula para que o trabalho de todas as partículas seja executado praticamente ao mesmo 
tempo. A carga de trabalho de cada thread é similar pois em uma simulação de fluidos espera-se que a médias de vizinhos por partícula seja constante, na ordem de 56 vizinhos em uma simulação 3D, devido ao uso da estrutura de grade virtual.

1 Inicialização do sistema;

2 repita

3 Inicialize a estrutura de detecção de vizinhança para acelerar o processo;

$4 \quad$ Para todas partículas faça em paralelo

$5 \quad$ Atualize a densidade;

6 fimpara

7 Para todas partículas faça em paralelo

8

17 até tempo $=$ tempo máximo ou $n^{o}$ de iterações $=n^{o}$ máximo de iterações;

Algoritmo 4: Algoritmo SPH paralelo.

\subsubsection{Modelo SPH simples}

O modelo SPH "simples" é baseado no modelo feito por Müller et al. (2003). Esta é uma formulação newtoniana fracamente compressível para uso interativo, resultando na troca precisão por desempenho. Este modelo usa núcleos especializados descritos na Seção 2.2.5.

\subsubsection{Modelo SPH viscoso}

O modelo "viscoso" é voltado para animações de fluidos não-newtonianos, este modelo difere do modelo simples na parte relativa aos cálculos das forças viscosas, mais precisamente da aproximação SPH do tensor extra-tensão. O cálculo das demais forças é novamente baseado no método proposto por Müller et al. (2003). Essa combinação de técnicas resulta em um método capaz de capturar com fidelidade o efeito de jato oscilante em fluidos viscosos, além de ser adequado para aplicações interativas. Em particular, o núcleo SPH cúbico 
foi escolhido para o cálculo do tensor extra-tensão por por fornecer uma animação mais realística e com menor esforço computacional. Do ponto de vista do desempenho, o núcleo SPH quártico (2.12) foi investigado, por não ser um polinômio por partes, e assim mais adequado para a GPU.

Este modelo viscoso é bem diferente em custo computacional desde que exige 3 iterações de somatório, em vez de apenas 2 . Isto porque o cálculo da força de tensão depende do tensor de velocidade que por sua vez depende do cálculo da densidade. Com isso temos o algoritmo 5.

1 Inicialização do sistema;

2 repita

3 Inicialize a estrutura de detecção de vizinhança para acelerar o processo;

$4 \quad$ Para todas partículas faça em paralelo

$5 \quad$ Atualize a densidade;

6 fimpara

7 Para todas partículas faça em paralelo

8 Calcule as forças dos tensores de tensão;

9 fimpara

10 Para todas partículas faça em paralelo

11 Calcule as forças de pressão e viscosidade;

12 Calcule a aceleração;

13 fimpara

14 Para todas partículas faça em paralelo

15

16

17

18

19

Atualize $v_{i}$ e $p_{i}$ com o integrador temporal;

Aplique as condições de fronteira;

\section{fimpara}

tempo $=$ tempo $+\Delta t$

$\mathrm{n}^{\circ}$ de iterações $=\mathrm{n}^{\circ}$ de iterações +1 ;

20 até tempo $=$ tempo máximo ou $n^{o}$ de iterações $=n^{o}$ máximo de iterações;

Algoritmo 5: Algoritmo SPH Viscoso paralelo.

\subsection{Emissão de partículas}

Para a simulação do problema de jato oscilante temos uma condição para emissão de partículas, em que a velocidade de emissão uniforme para a entrada do emissor deve ser especificada (Xu et al., 2013a). Para tal, um conjunto de partículas são colocadas na entrada do emissor e suas respectivas velocidades igual a velocidade de emissão. Afim de manter a velocidade de emissão uniforme, um novo conjunto de partículas são inseridas na entrada do emissor logo que as partículas originais percorram uma distância igual 
ao espaçamento inicial. Deste modo o número de partículas na entrada do emissor se mantém constante. Ao longo do tempo o número de partículas no interior do domínio computacional aumenta. A emissão de partículas termina quando o número total de partículas especificado é alcançado. 


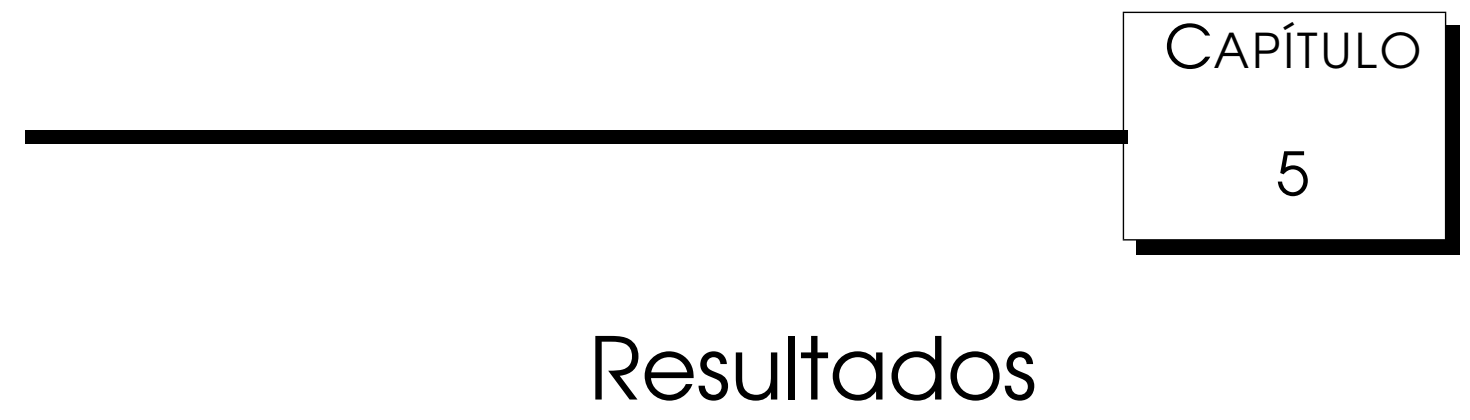

ara demonstrar a eficiência da GPU, a implementação do sistema foi feita de maneira para suportar a execução da simulação tanto em GPU como em CPU. E deste modo comparar e calcular o speedup obtido. Simulações com vários arranjos de parâmetros foram utilizadas para comparar visualmente o comportamento do jato oscilante.
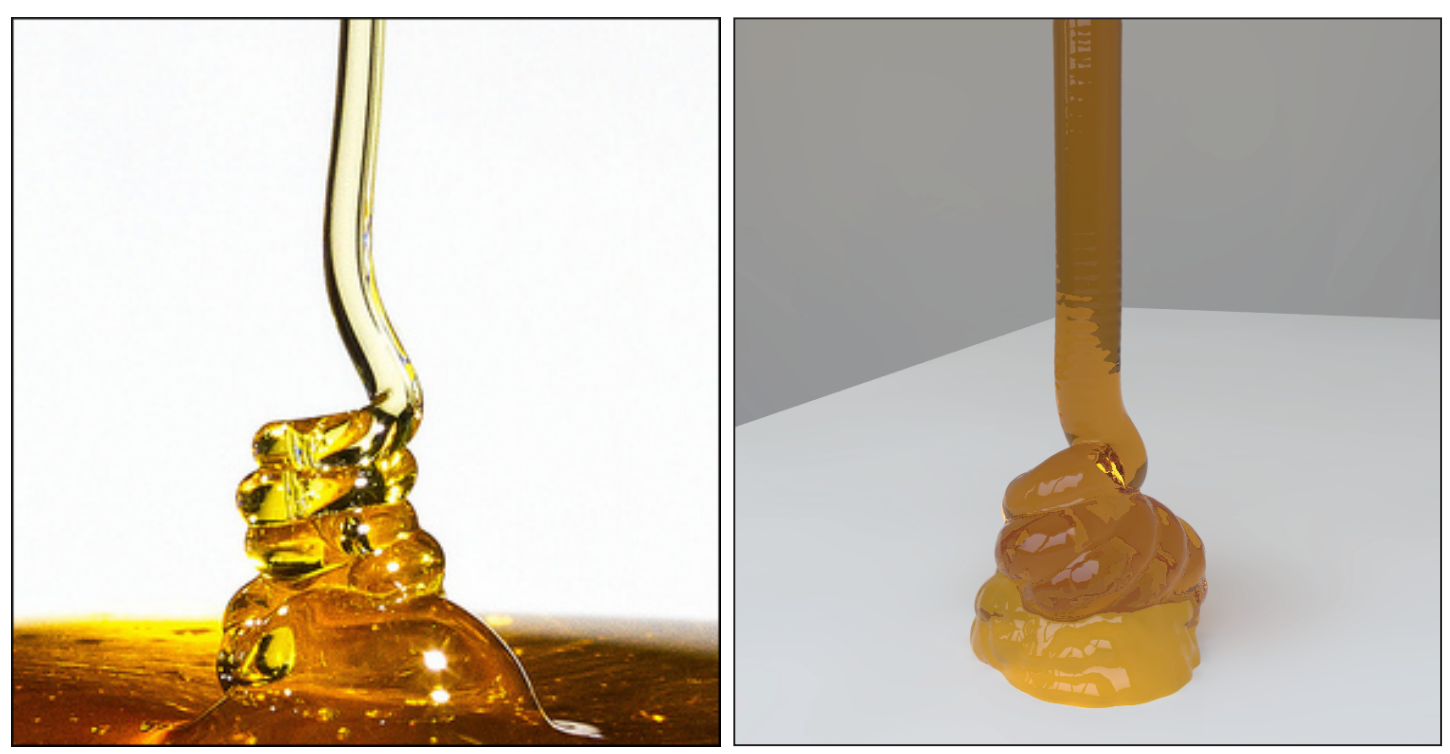

Figura 5.1: Comparação com a realidade. 


\subsection{CPU x GPU}

A modo de calcular o speedup da GPU em relação a CPU, testes foram realizados com 3 tipos de CPU e 3 tipos de GPU. Em cada teste foram executadas 1000 iterações da simulação, tanto no modo simples como no viscoso, e somado o tempo decorrido em milissegundos.

As seguintes CPUs foram utilizadas:

- Intel i5 750

- Intel i7 980X

- Intel i5 3750

As seguintes GPUs foram utilizadas:

- NVIDIA GTX 285

- NVIDIA GTX 580

- NVIDIA GTX 650

Tanto as CPUs e GPUs estão listadas em ordem de lançamento.

\subsubsection{Modelo simples}

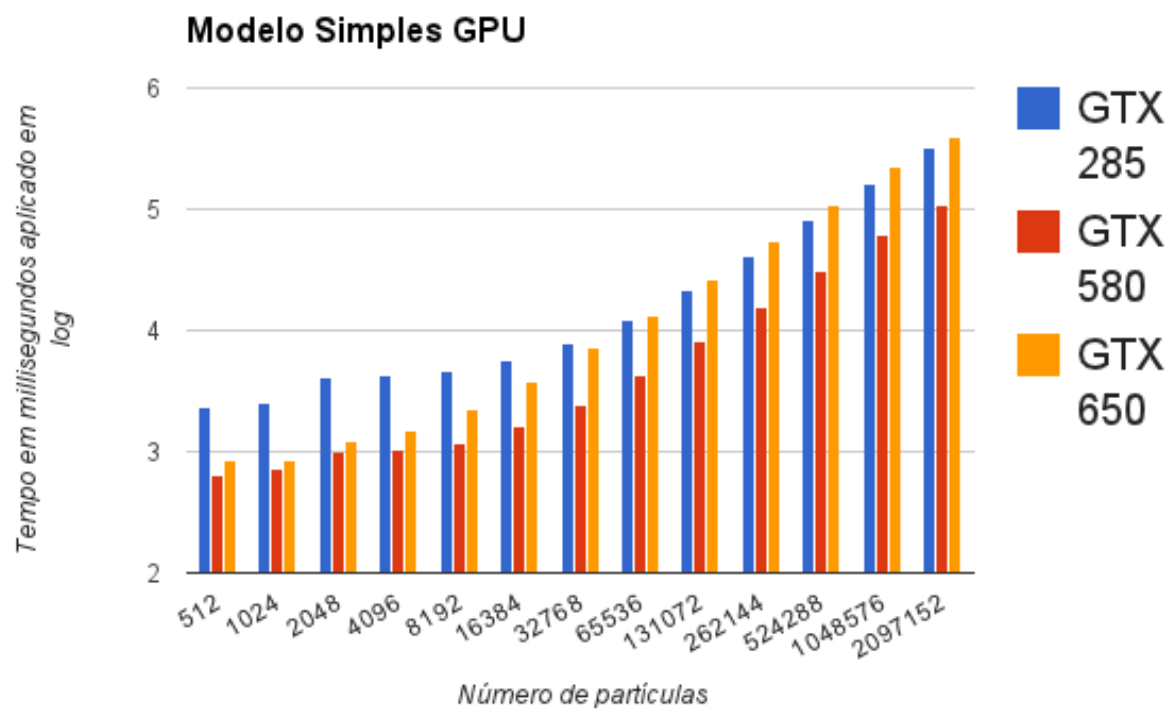

Figura 5.2: Modelo simples em GPU. 


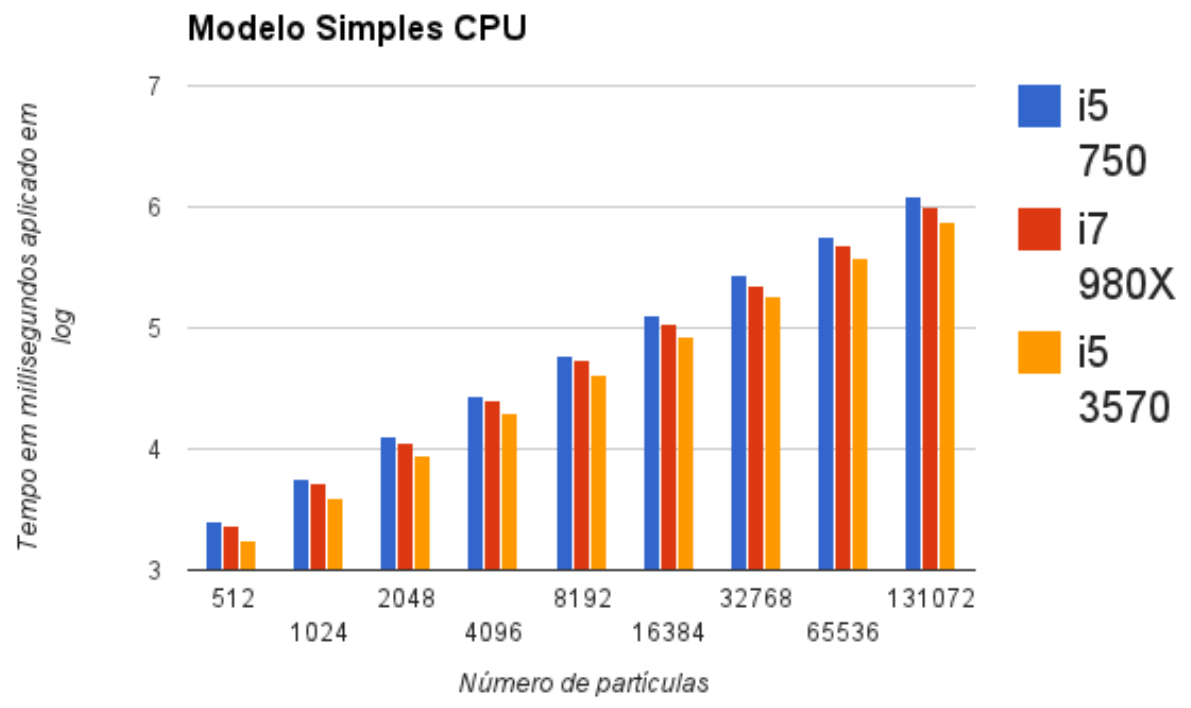

Figura 5.3: Modelo simples em CPU.

Observando a Figura 5.2 notamos que sua escala de crescimento aumenta consideravelmente a partir de 262144 partículas, diferentemente da Figura 5.3 que o crescimento acompanha o número de partículas.

Na Figura 5.4 temos o comparativo de tempo entre o melhor tempo de CPU contra o melhor tempo de GPU. Podemos observar que até 1024 partículas os tempos são equivalentes em nossa perspectiva, mas logo após o tempo em GPU se torna insignificante se comparado ao tempo em CPU.

\subsubsection{Modelo viscoso}

Observando a Figura 5.5 notamos que sua escala de crescimento aumenta consideravelmente a partir de 262144 partículas, diferentemente da Figura 5.6 que o crescimento acompanha o número de partículas.

Na Figura 5.7 temos o comparativo de tempo entre o melhor tempo de CPU contra o melhor tempo de GPU. Podemos observar que até 1024 partículas os tempos são equivalentes em nossa perspectiva, mas logo após o tempo em GPU se torna insignificante se comparado ao tempo em CPU.

\subsubsection{Modelo simples X Modelo viscoso}

Em relação aos modelos simples e viscoso em CPU visto na Figura 5.8 o padrão do tempo em relação ao número de partículas se mantém, mas vemos que o modelo viscoso aumenta sua diferença em relação ao simples ao longo 


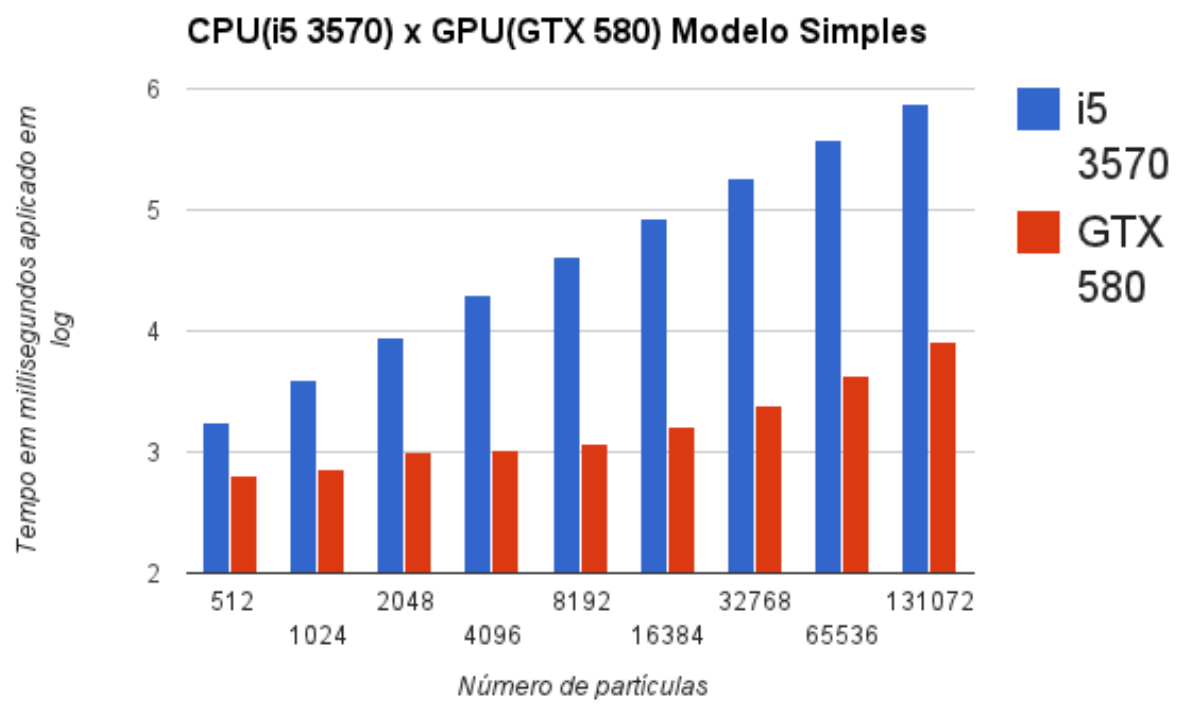

Figura 5.4: Análise computacional do modelo simples em relação aos melhores resultados de CPU e GPU.

que o número de partículas aumenta. Essa relação em GPU é ilustrada na Figura 5.9, nota-se o mesmo comportamento visto na análise em CPU.

\subsubsection{Speedup}

\begin{tabular}{|c|c|c|}
\hline Número de partículas & Modelo Simples & Modelo Viscoso \\
\hline 512 & 2.76 & 3.83 \\
\hline 1024 & 5.45 & 7.92 \\
\hline 2048 & 8.87 & 12.30 \\
\hline 4096 & 18.85 & 26.23 \\
\hline 8192 & 36.18 & 42.96 \\
\hline 16384 & 52.77 & 55.52 \\
\hline 32768 & 73.68 & 64.33 \\
\hline 65536 & 86.32 & 72.19 \\
\hline 131072 & 93.05 & 77.66 \\
\hline
\end{tabular}

Tabela 5.1: Speedup CPU(i5 3570) x GPU(GTX 580).

A tabela 5.1 exibe o melhor speedup do modelo simples e viscoso. Utilizandose do melhor tempo em CPU e GPU, das utilizadas como teste, vemos como a GPU escala com o tamanho da simulação a ser tratada. Ela compara o desempenho da aplicação rodando uma simulação de quebra de barragem sequencialmente em CPU e em paralelo em GPU. Os parâmetros para o modelo viscoso são: $K=1, n=1, \nu_{0}=0.05$, e $\nu_{\infty}=0.005$. 


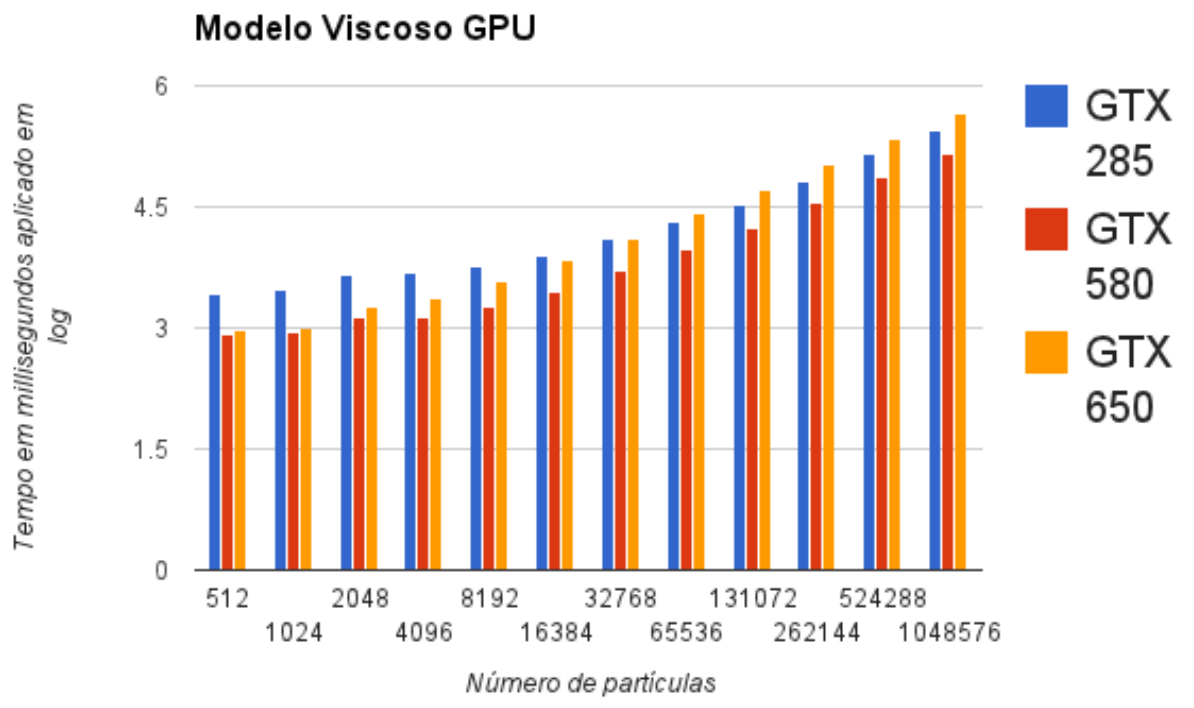

Figura 5.5: Modelo viscoso GPU

\subsection{Jato oscilante}

Foram feitos vários testes da simulação do jato oscilante, alterando viscosidades, passo de tempo, largura do emissor e altura. A Figura 5.10 nos mostra um passo onde conseguimos notar a formação da oscilação, mas por estar com um passo de tempo elevado as características desejadas são atingidas parcialmente. Nesse sentido temos uma relação onde ganhamos desempenho para perda de características do jato oscilante, deve-se escolher os parâmetros da simulação de modo que essa relação se equipare.

Testes foram feitos com o emissor em movimento como vemos na Figura 5.11 onde a superfície livre é capturada usando um método de geração de malha explícita. Note como os detalhes das dobras do fluido são capturadas de forma satisfatória.

Na Figura 5.12 temos uma sequência de passos do jato oscilante onde as partículas são representadas por esferas e o mapa de cores representa a variação de viscosidade do fluido variando de regiões de baixa viscosidade (azul) até regiões de alta viscosidade (vermelho).

Diferente da Figura 5.12 a Figura 5.13 está com um emissor retangular. Nota-se uma grande oscilação no fluido, onde nesses passos o total de partículas se aproxima de 32000 e pode-se observar pelo mapa de cores onde a variação de viscosidade aparece formando uma característica de dobras a esta simulação. 


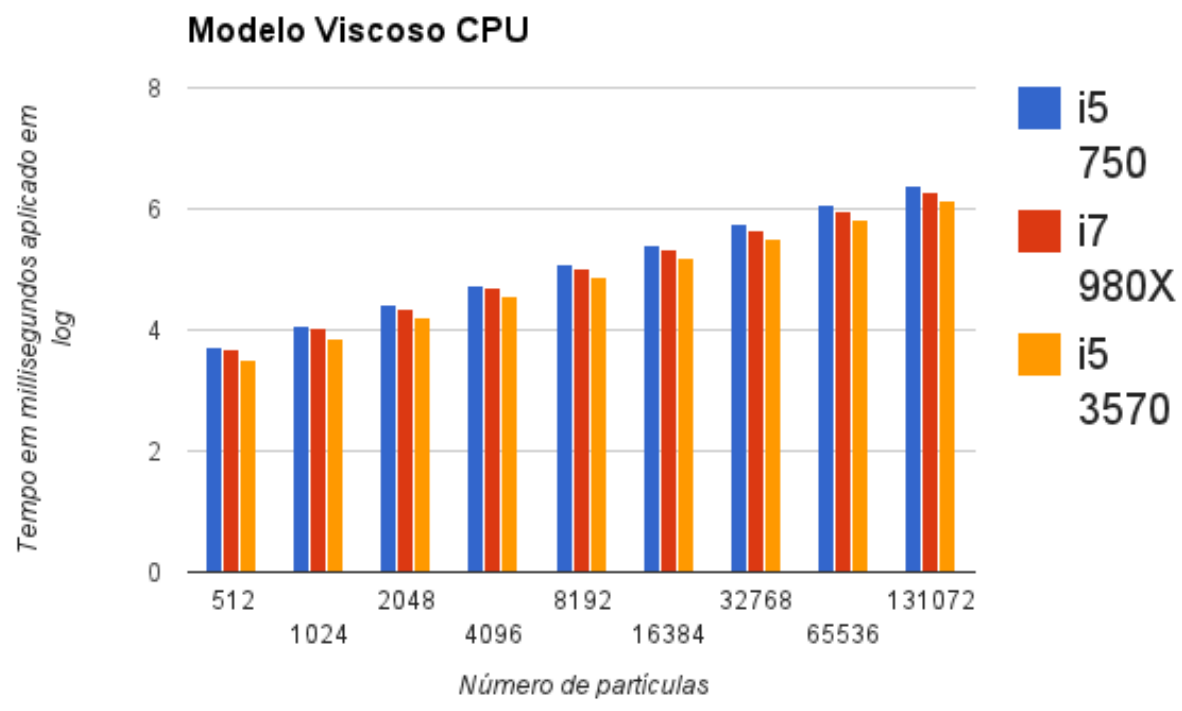

Figura 5.6: Modelo viscoso CPU

Na Figura 5.14 podemos ver com detalhes o início da formação da oscilação do fluido viscoso, a cada passo é vista uma mudança de direção na base do fluido. A Figura 5.15 mostra a animação com a variação de $k$ no emissor retangular, pode-se ver a distribuição de partículas e a mudança de direção do jato de partículas.

Na Figura 5.16 é demonstrado o efeito dos parâmetros $n, \nu_{\infty}$ e $\nu_{0}$ no método, fixando $K=1$. Os gráficos da esquerda mostram a variação da viscosidade sob a influência desses parâmetros, variando tanto $n$ (acima) ou $\left[\nu_{\infty}, \nu_{0}\right]$ (abaixo). A direita, simulações correspondentes com essas combinações de parâmetros são mostradas. As três primeiras colunas mostram a função de viscosidade, estabelecendo $K=1 \mathrm{e}\left[\nu_{\infty}, \nu_{0}\right]=[0.2,2]$, variando os parâmetros de índice $n=0.5,1$ e 10. As últimas três colunas mostram a função de viscosidade dependendo apenas de $\nu_{\infty}$ e $\nu_{0}$. Fixando $n=1$, diferentes faixas de viscosidade foram testadas $\left[\nu_{\infty}, \nu_{0}\right]:[0.2,2],[0.002,2]$ e $[0.2,20]$.

Se comparada a Figura 5.17 a Figura 5.18 possui mais detalhes pois foi utilizado um passo de tempo menor, variando apenas este parâmetro podemos obter resultados aparentemente diferentes. 


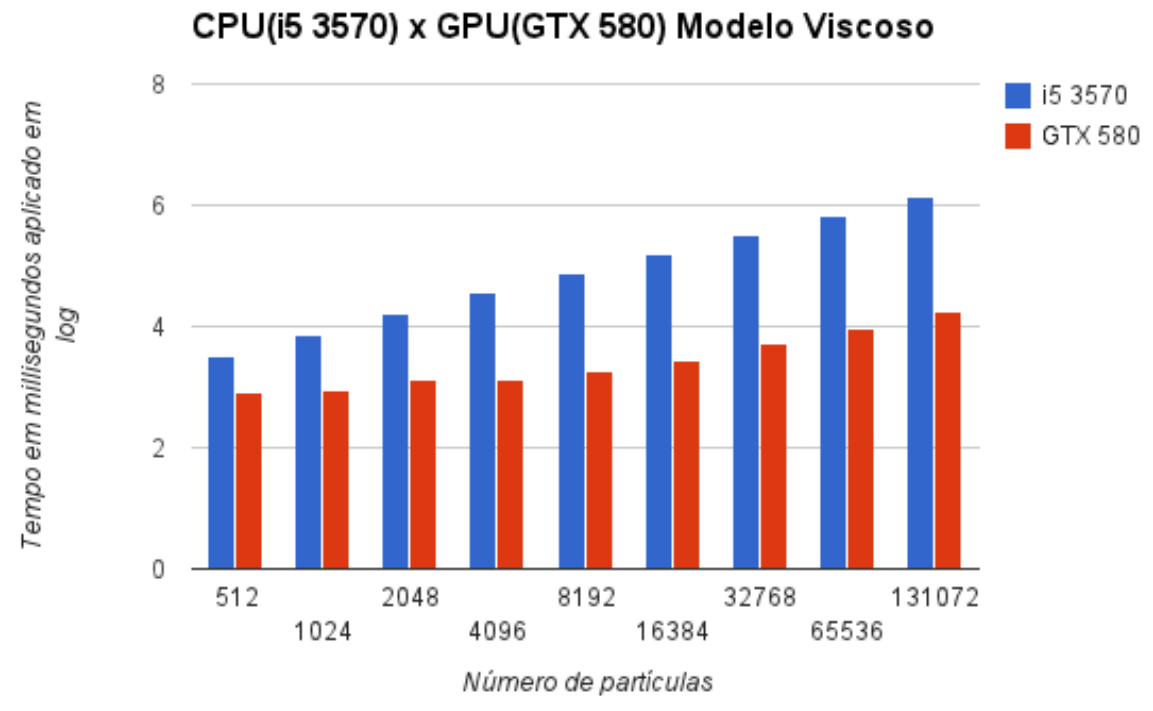

Figura 5.7: Viscoso CPU x GPU

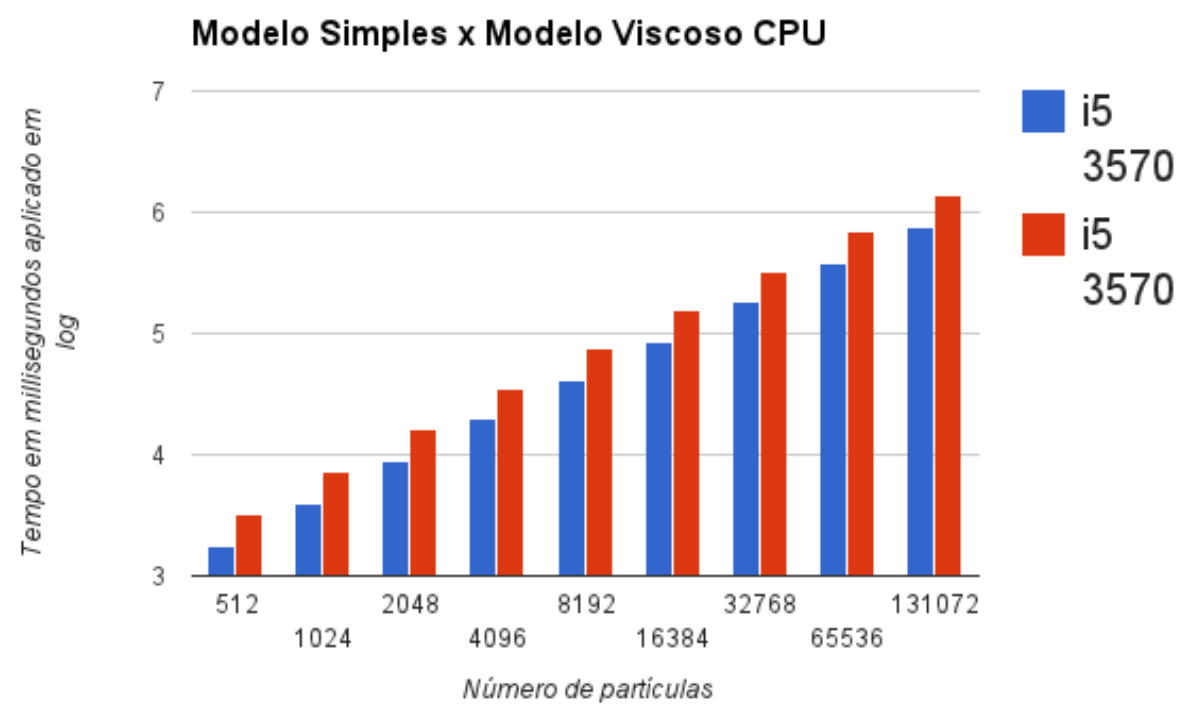

Figura 5.8: Modelo simples X Modelo viscoso CPU 


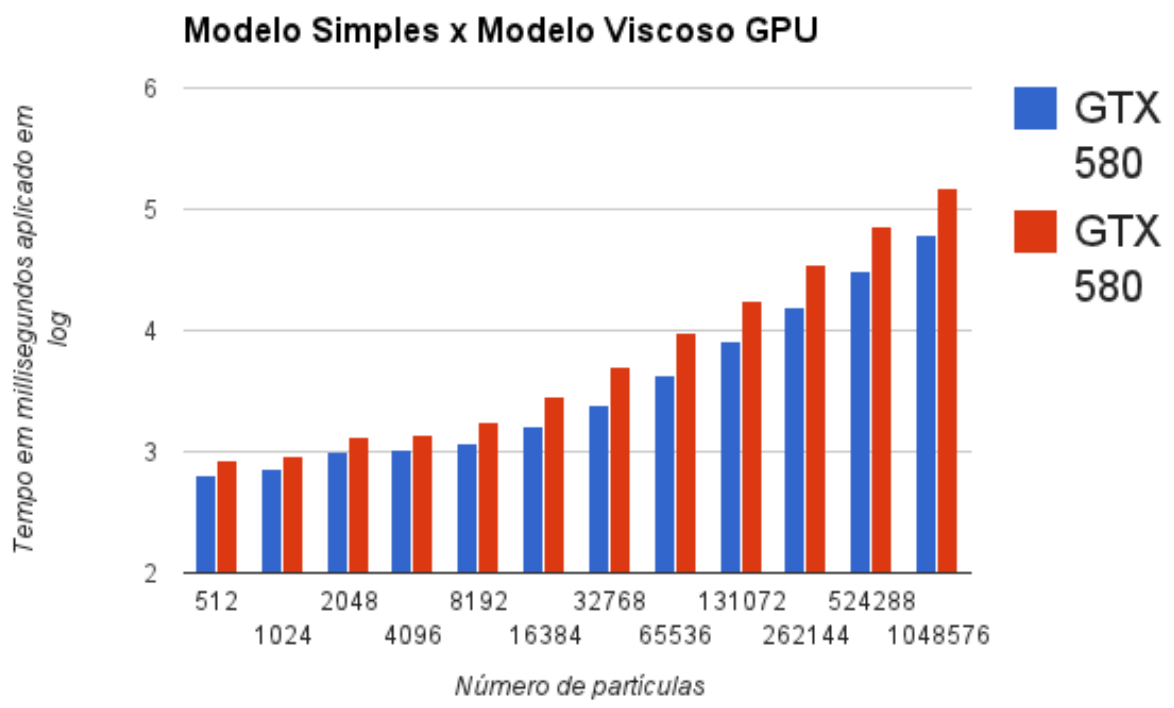

Figura 5.9: Modelo simples X Modelo viscoso GPU
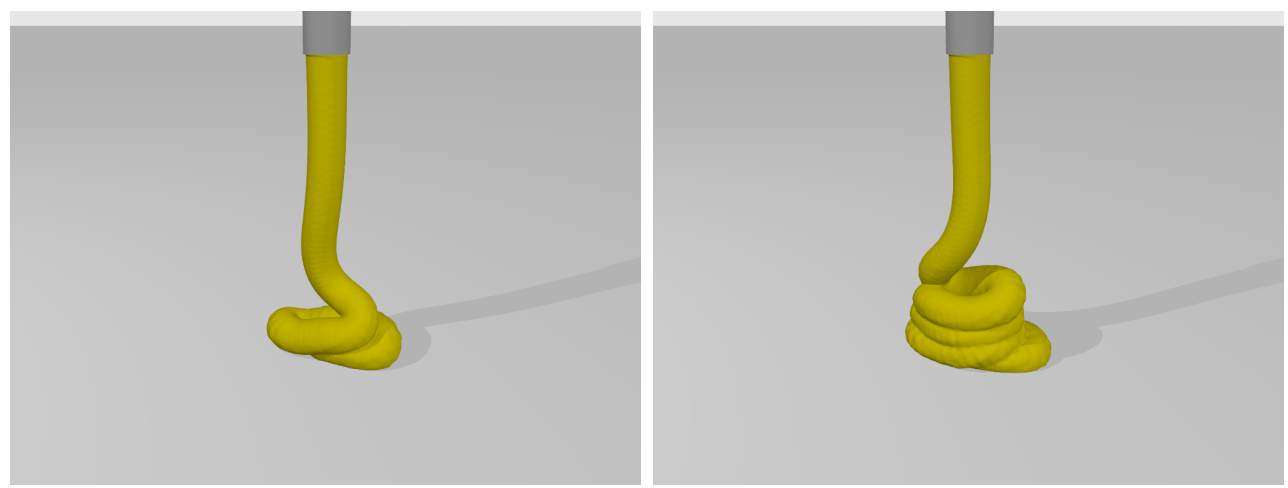

Figura 5.10: Passos da simulação de jato oscilante com a superfície livre sendo representada de forma implícita.

Figura 5.11: Emissor em movimento 


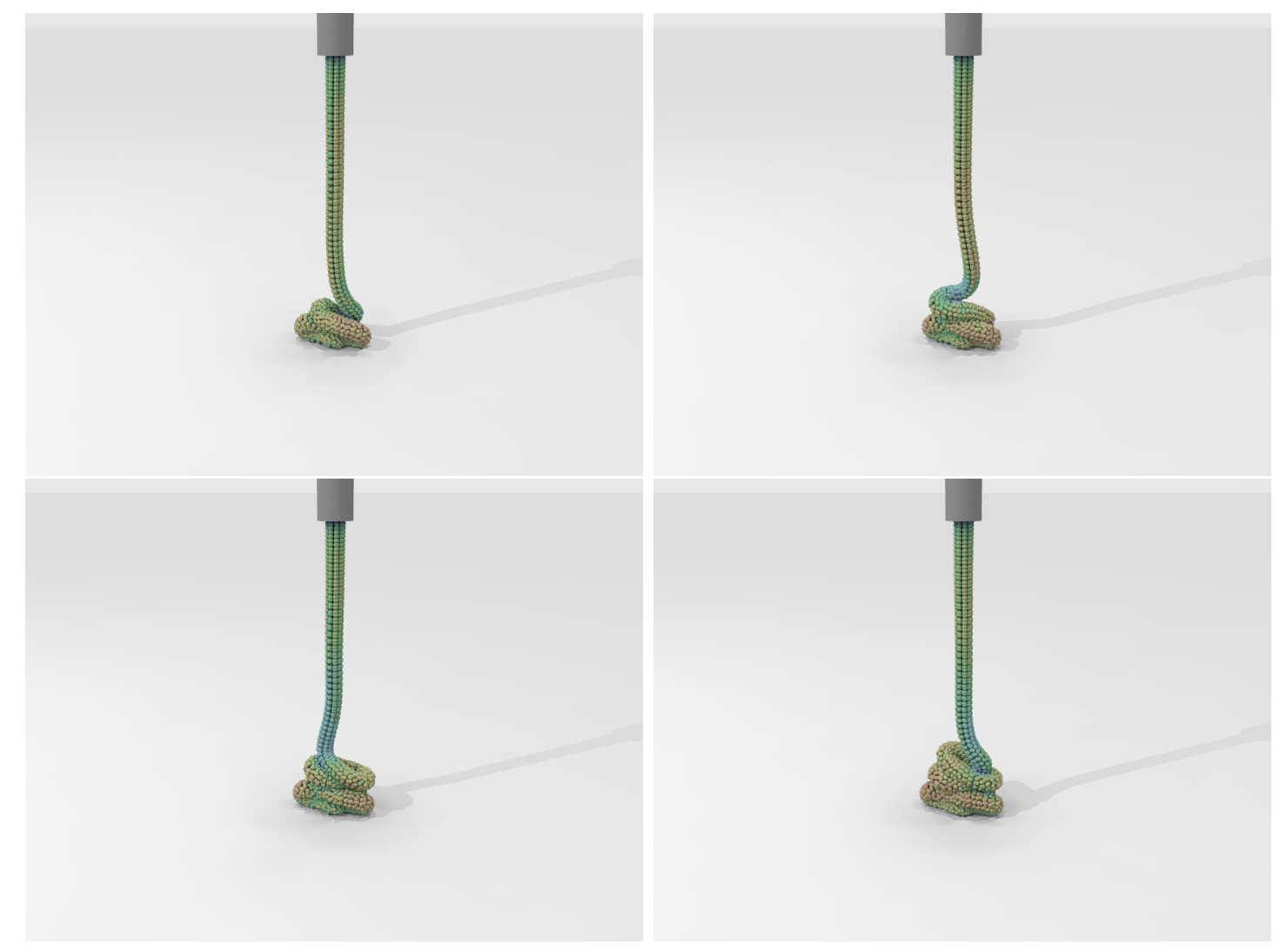

Figura 5.12: Passos simulação jato oscilante.
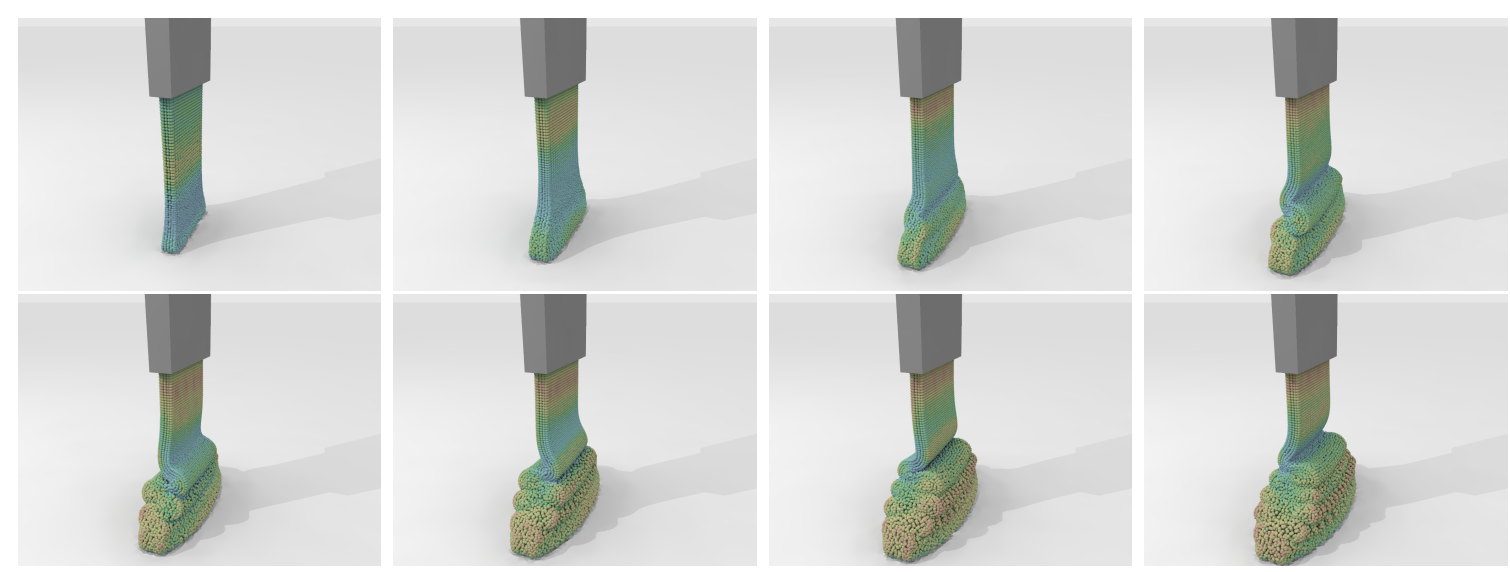

Figura 5.13: Passos de simulação do jato oscilante. Emissor retangular 


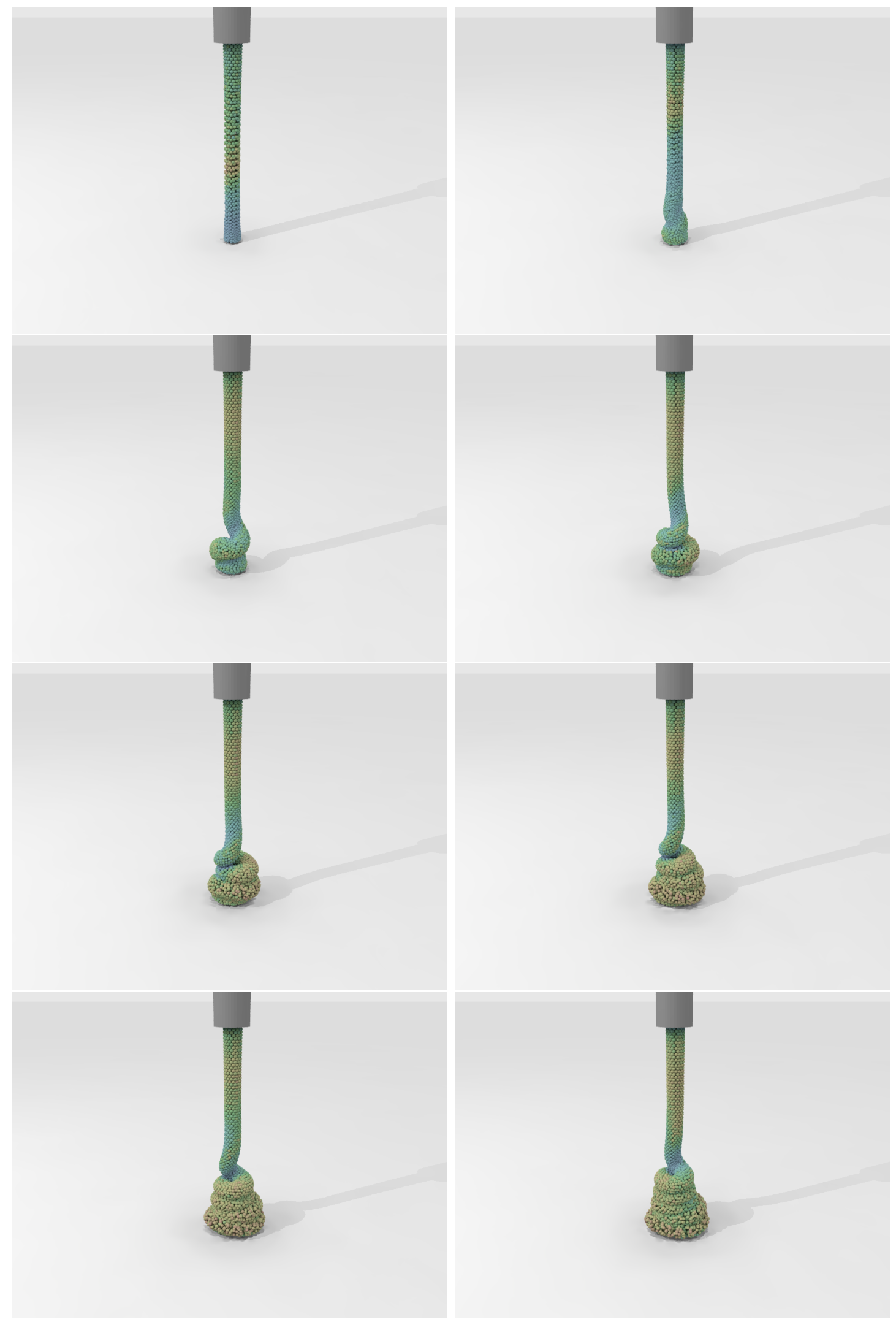

Figura 5.14: Passos simulação jato oscilante. Detalhe para o inicio da simulação 


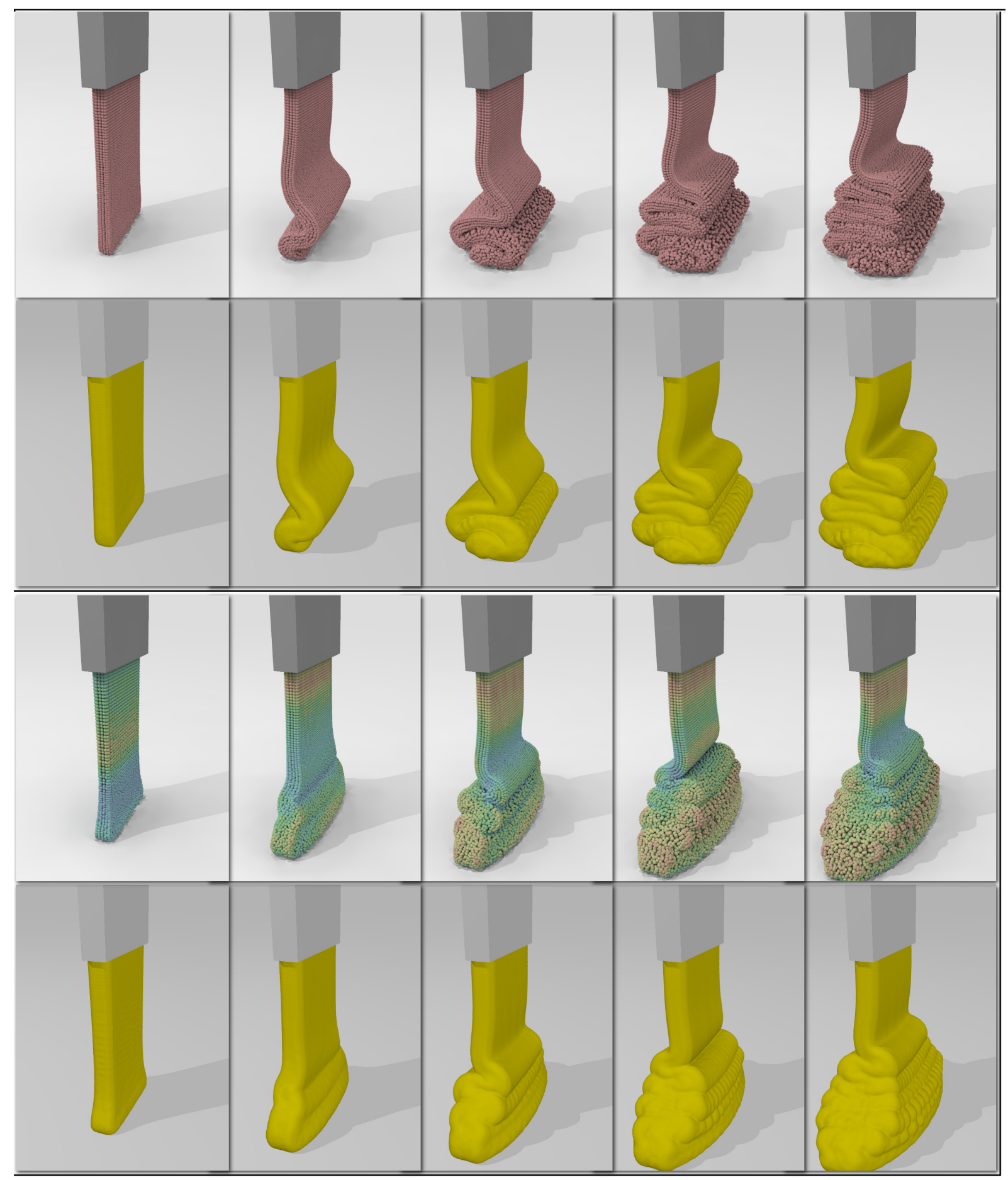

Figura 5.15: Passos da simulação do jato oscilante. Emissor retangular variado o $\mathrm{K}$. 


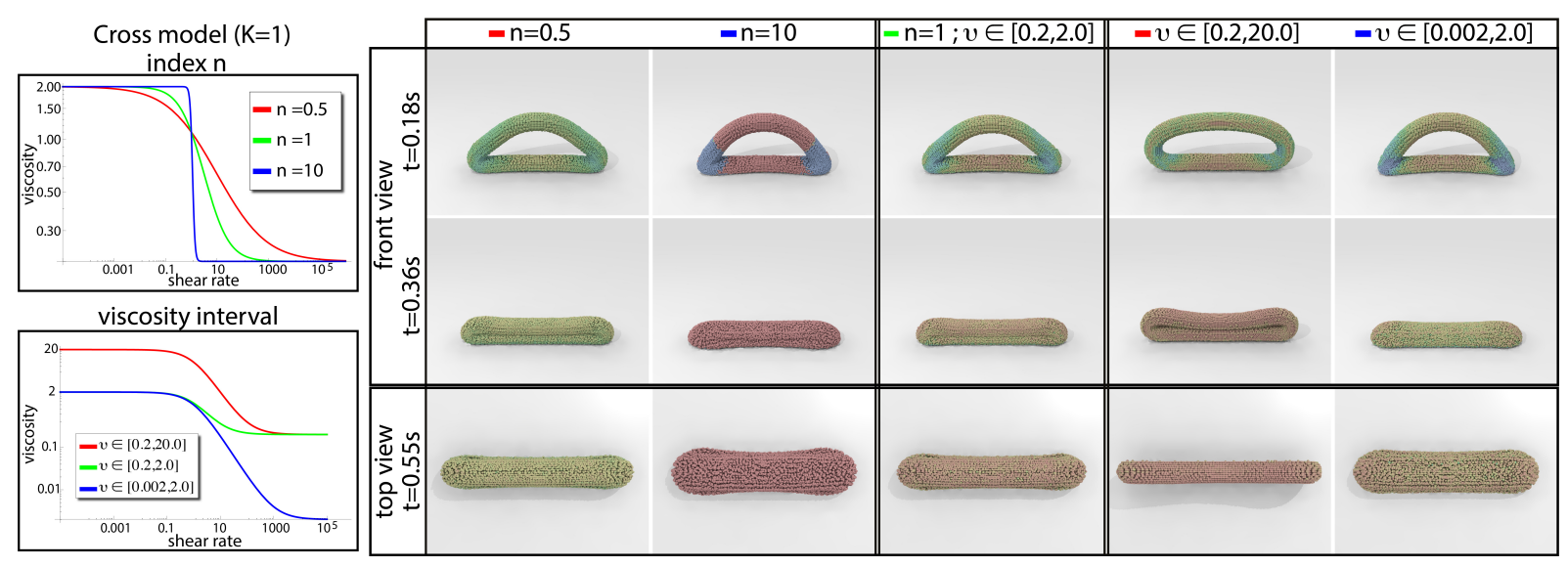

Figura 5.16: Passos de uma simulação de um torus com variação de parâmetros. 


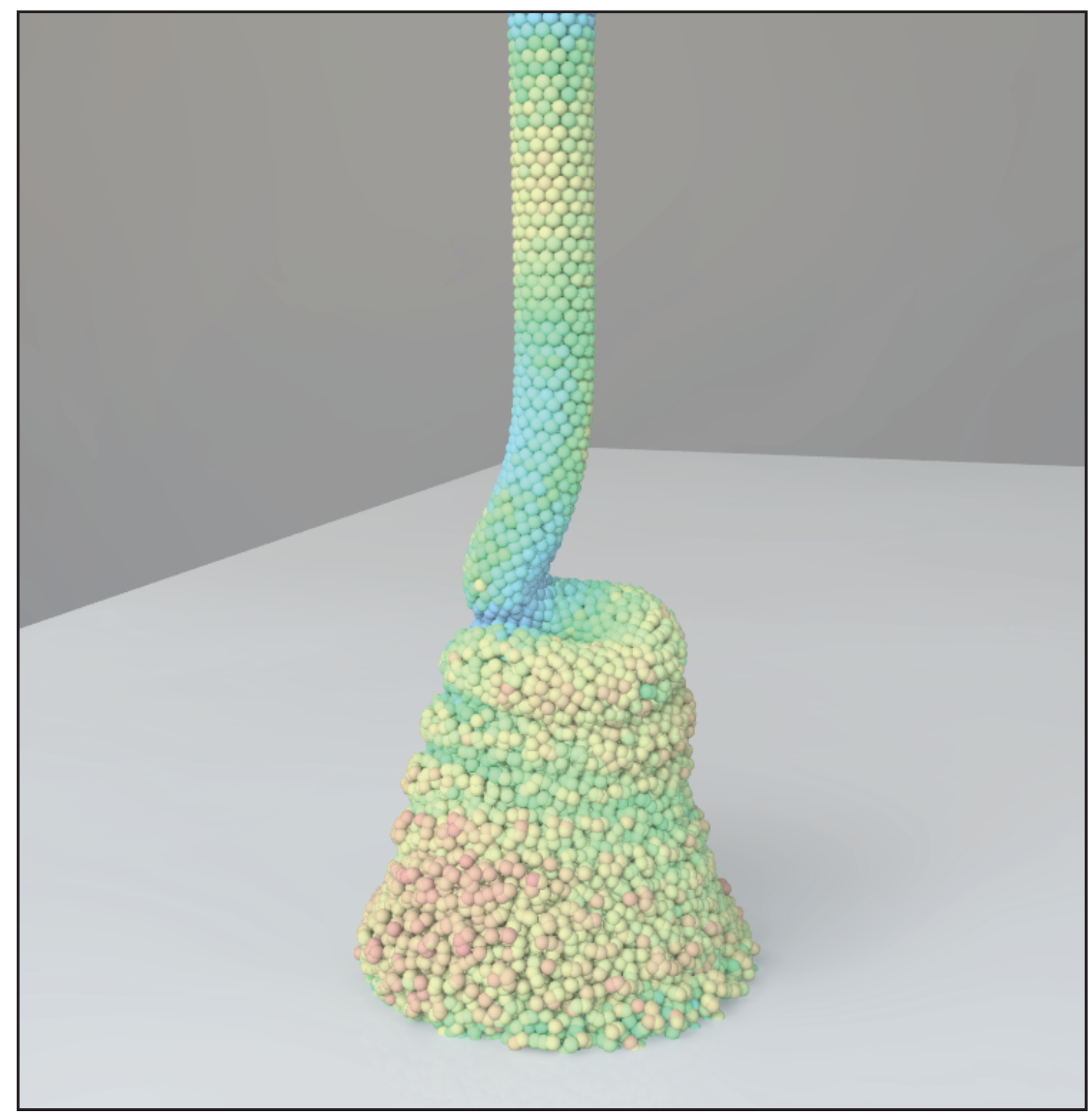

Figura 5.17: Passo de simulação do jato oscilante representado por particulas. 


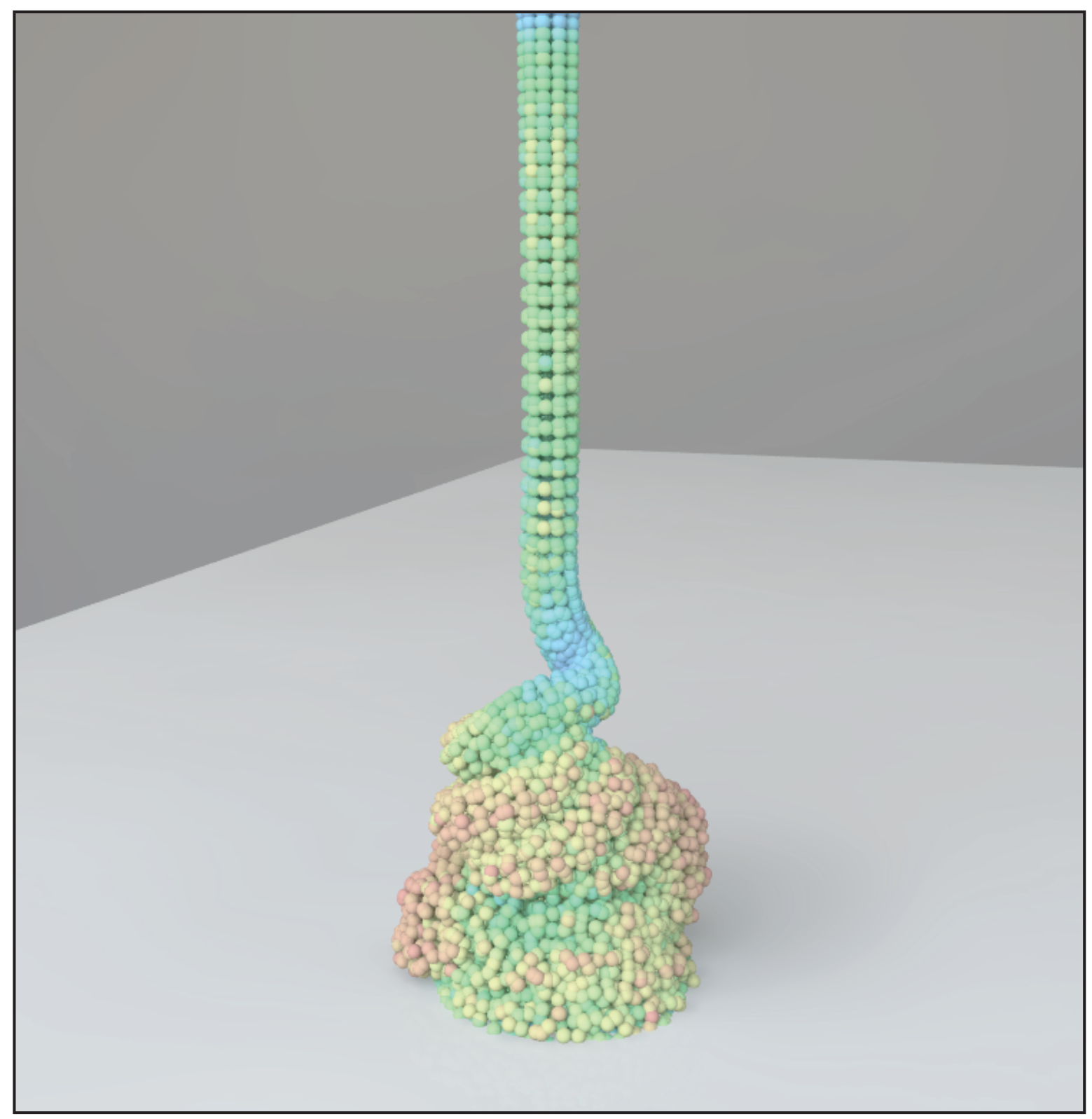

Figura 5.18: Passo de simulação do jato oscilante representado por particulas. 


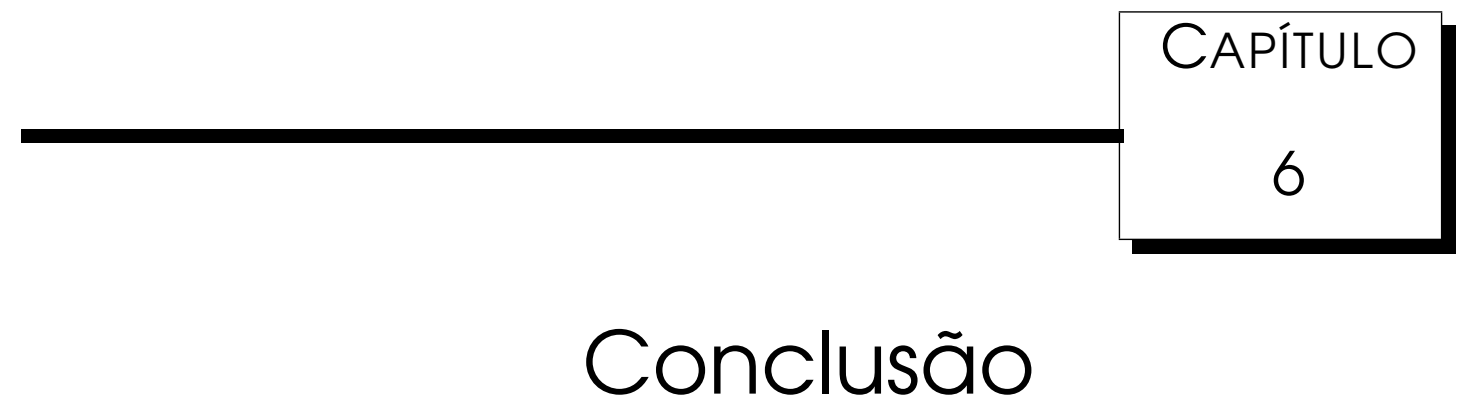

odemos concluir que simular fluidos viscosos com o fenômeno do jato
oscilante é difícil de reproduzir com grandes passos de tempo. Foram
feitas simulações de fluidos não-newtonianos, utilizando-se como modelo reológico de Cross.

Uma descrição completa de SPH foi apresentada mostrando que esse método é ideal para simulações interativas em GPU por causa da alta eficiência e porque é altamente paralelizável.

Um arcabouço para simulações em SPH para GPU foi desenvolvido e implementado. Usando essa estrutura 2 modelos SPH foram implementados. Um modelo simples que é uma reimplementação de um modelo SPH que é adequado para fluidos de baixa viscosidade em simulações interativas e um modelo viscoso que inclui suporte para fluidos não-newtonianos.

\subsection{Desempenho}

Como podemos observar em 5, com o aumento da escala do problema o desempenho em CPU se distancia da GPU. Demonstrando assim a escolha de utilizar GPU para este trabalho.

Comparações entre GPUs foram feitas demostrando as diferenças no desempenho entre as gerações da arquitetura CUDA. 


\subsection{Trabalhos Futuros}

Futuramente devemos reproduzir com mais fidelidade o jato oscilante com passos de tempo maiores. Uma possibilidade interessante é estender o método para fluidos multifásicos.

A implementação em GPU deve ser revista para se beneficiar das novas arquiteturas CUDA presente no mercado atualmente, assim ganhando um melhor desempenho.

Pode-se melhorar a renderização da simulação em tempo real, de modo que a reconstrução de superfície pode-se tornar uma forma mais correta da superfície livre do fluido. Deve-se adicionar suporte para malhas arbitrárias, de modo a criar cenas mais complexas para a simulação.

Um grande avanço seria a implementação com suporte a várias GPUs, fazendo com que seja possível melhorar a precisão e desempenho. Isso exigiria de alguma forma dividir o domínio de simulação de forma que a carga entre as GPUs seja equilibrada, vemos que Fleissner e Eberhard (2007) propuseram tal método para balanceamento de carga paralela. Um modo de estender a comparação com CPU é também utilizar da possibilidade de paralelização também em CPU (Ihmsen et al., 2011) da implementação.

Finalmente, pretendemos também explorar a versão incompressível do SPH (ISPH) usando o método da projeção (Cummins e Rudman, 1999) em CUDA com a finalidade de simular jatos oscilantes $3 \mathrm{D}$, algo inédito tanto na literatura de física computacional como também de animação. 


\section{Referências Bibliográficas}

Batty, C. e Bridson, R. (2008). Accurate viscous free surfaces for buckling, coiling, and rotating liquids. In Symposium on Computer Animation, páginas 219-226. Citado nas páginas vii e 4.

Bonito, A., Picasso, M., e Laso, M. (2006). Numerical simulation of 3d viscoelastic flows with free surfaces. Journal of Computational Physics, 215(2):691 - 716. Citado na página 20.

Crespo, A. J. C. (2008). Application of the Smoothed Particle Hydrodynamics model SPHysics to free-surface hydrodynamics. Tese de Doutorado, PhD thesis. Citado nas páginas 11 e 13.

Cruickshank, J. O. (1988). Low-reynolds-number instabilities in stagnating jet flows. Journal of Fluid Mechanics, 193:111-127. Citado nas páginas 17 e 20 .

Cruickshank, J. O. e Munson, B. R. (1981). Viscous fluid buckling of plane and axisymmetric jets. Journal of Fluid Mechanics, 113:221-239. Citado nas páginas 17 e 20 .

Cummins, S. e Rudman, M. (1999). An SPH projection method. Journal of Computational Physics, 152(2):584-607. Citado na página 56.

Desbrun, M. e Cani, M. P. (1996). Smoothed particles: A new paradigm for animating highly deformable bodies. In Computer Animation and Simulation '96, páginas 61-76. Proc. of EG Workshop on Animation and Simulation, Springer-Verlag. Citado na página 15.

Fleissner, F. e Eberhard, P. (2007). Load balanced parallel simulation of particle-fluid dem-sph systems with moving boundaries. In Bischof, C. H., 
Bücker, H. M., Gibbon, P., Joubert, G. R., Lippert, T., Mohr, B., e Peters, F. J., editors, PARCO, volume 15 of Advances in Parallel Computing, páginas 37-44. IOS Press. Citado na página 56.

Gingold, R. A. e Monaghan, J. J. (1977a). Smoothed particle hydrodynamics - theory and application to non-spherical stars. Royal Astronomical Society, Monthly Notices, vol. 181. Citado na página 9.

Gingold, R. A. e Monaghan, J. J. (1977b). Smoothed particle hydrodynamics: theory and application to non-spherical stars. Monthly Notices of the Royal Astronomical Society, 181:375-389. Citado nas páginas vii, 2, 3, e 12.

Goktekin, T. G., Bargteil, A. W., e O’Brien, J. F. (2004). A method for animating viscoelastic. ACM Transactions on Graphics, 23(3):463-468. Citado nas páginas vii e 3 .

Harris, M., Sengupta, S., e Owens, J. D. (2007). Parallel prefix sum (scan) with cuda. In Nguyen, H., editor, GPU Gems 3. Addison Wesley. Citado na página 34.

Herault, A., Bilotta, G., e Dalrymple, R. A. (2010). SPH on GPU with CUDA. Journal of Hydraulic Research, 48(Extra Issue):74-79. Citado na página 36.

Hoberock, J. e Bell, N. (2010). Thrust: A parallel template library. Version 1.7.0. Citado na página 34 .

Ihmsen, M., Akinci, N., Becker, M., e Teschner, M. (2011). A parallel sph implementation on multi-core cpus. Computer Graphics Forum, 30(1):99112. Citado na página 56.

Kelager, M. (2006). Lagrangian Fluid Dynamics Using Smoothed Particle Hydrodynamics. Citado na página 23.

Krog, Ø. E. e Elster, A. C. (2012). Fast gpu-based fluid simulations using sph. In Applied Parallel and Scientific Computing, páginas 98-109. Springer. Citado na página 37.

Liu, M., Liu, G., e Lam, K. (2003). Constructing smoothing functions in smoothed particle hydrodynamics with applications. Journal of Computational and Applied Mathematics, 155(2):263-284. Citado na página 14.

Lucy, L. (1977a). A numerical approach to the testing of the fission hypothesis. Astronomical Journal, 82:1013-1024. Citado na página 9. 
Lucy, L. B. (1977b). Numerical approach to testing the fission hyphotesis. Astronomical Journal, 82:1013-1024. Citado na página 2.

Monaghan, J. e Kovharyan, A. (1995). SPH simulating of multi-phase flow. Computater Physics Communications, (87):225-235. Citado na página 3.

Monaghan, J. e Latanzio, J. (1985). A refined particle method for astrophysical problems. Astronomy and Astrophysics, 149(1):135-143. Citado na página 12.

Morris, J. (1996). Analysis of smoothed particle hydrodynamics with applications. Tese de Doutorado, Monash University. Citado na página 3.

Morris, J., Fox, P., e Zhu, Y. (1997). Modeling low Reynolds number incompressible flows using SPH. Journal of Computational Physics, 136(1):214226. Citado nas páginas 13 e 15.

Müller, M., Charypar, D., e Gross, M. (2003). Particle-based fluid simulation for interactive applications. In Symposium on Computer Animation, páginas 154-159. Citado nas páginas $1,2,3,14,16,37$, e 38.

Nogueira, A., Prata, E., e Velho, L. (2004). Visualização de objetos tridimensionais baseada em interpolação projetiva. Citado na página 1 .

Owens, R. G. e Phillips, T. N. (2002). Computational Rheology. Imperial College Press. Citado na página 2.

Paiva, A., Petronetto, F., Lewiner, T., e Tavares, G. (2009a). Particle-based viscoplastic fluid/solid simulation. Computer-Aided Design, 41(4):306-314. Citado nas páginas 20 e 24.

Paiva, A., Petronetto, F., Lewiner, T., e Tavares, G. (2009b). Simula?ão de fluidos sem malha, uma introdu?ão do método SPH. IMPA. Citado nas páginas $3,7,8,10,21$, e 23 .

Rafiee, A., Manzari, M., e Hosseini, M. (2007). An incompressible SPH method for simulation of unsteady viscoelastic free-surface flows. International Journal of Non-Linear Mechanics, 42(10):1210 - 1223. Citado nas páginas vii e 4 .

Sengupta, S., Harris, M., Zhang, Y., e Owens, J. D. (2007). Scan primitives for gpu computing. In Graphics Hardware 2007, páginas 97-106. ACM. Citado na página 34. 
Tome, M. F. e Mckee, S. (1999). Numerical simulation of viscous flow: buckling of planar jets. International journal for numerical methods in fluids, 29(6):705-718. Citado na página 20.

Wendland, H. (1995). Piecewise polynomial, positive definite and compactly supported radial functions of minimal degree. Advances in computational Mathematics, 4(1):389-396. Citado na página 13.

Wendland, H. (2006). Computational aspects of radial basis function approximation. Studies in Computational Mathematics, 12:231-256. Citado na página 13.

Xu, X., Ouyang, J., Yang, B., e Liu, Z. (2013a). Sph simulations of threedimensional non-newtonian free surface flows. Computer Methods in Applied Mechanics and Engineering, 256:101-116. Citado nas páginas 5, 37, e 39.

Xu, X., Ouyang, J., Yang, B., e Liu, Z. (2013b). \{SPH\} simulations of threedimensional non-newtonian free surface flows. Computer Methods in Applied Mechanics and Engineering, 256(0):101 - 116. Citado nas páginas 19 e 22. 